University of Tennessee Health Science Center

UTHSC Digital Commons

\title{
$5-2008$
}

\section{The Unfolded Protein Response Increases Production of Pro- Angiogenic Factors by Tumor Cell Lines}

\author{
Nan Liao \\ University of Tennessee Health Science Center
}

Follow this and additional works at: https://dc.uthsc.edu/dissertations

Part of the Medical Cell Biology Commons

\section{Recommended Citation}

Liao, Nan , "The Unfolded Protein Response Increases Production of Pro-Angiogenic Factors by Tumor Cell Lines" (2008). Theses and Dissertations (ETD). Paper 140. http://dx.doi.org/10.21007/ etd.cghs.2008.0182.

This Thesis is brought to you for free and open access by the College of Graduate Health Sciences at UTHSC Digital Commons. It has been accepted for inclusion in Theses and Dissertations (ETD) by an authorized administrator of UTHSC Digital Commons. For more information, please contact jwelch30@uthsc.edu. 


\title{
The Unfolded Protein Response Increases Production of Pro-Angiogenic Factors by Tumor Cell Lines
}

\begin{abstract}
The rapid growth and proliferation of tumor cells will be limited at a stage when they encounter inadequate levels of oxygen and nutrient supply within the poorly vascularized tumor mass. These severe conditions negatively affect the proper folding of nascent proteins in the endoplasmic reticulum (ER) and lead to accumulation of unfolded protein within ER which is referred to as ER stress. Consequently, it will trigger the unfolded protein response (UPR) signal pathway through ER membrane stress sensor proteins including activating transcription factor 6 (ATF6), inositol-requiring 1 (IRE1) and PKR-like ER localized kinase (PERK). The UPR is largely a cytoprotective response and is thought to contribute to tumor survival in the face of inadequate nutrients and oxygen. Microarray analyses were conducted on Daoy, a human medulloblastoma line that was treated with thapsigargin, which activates the UPR by depleting $\mathrm{Ca}+$ from the ER. In addition to the expected UPR targets, we found that ER stress inducing agents led to the transcriptional induction of several pro-angiogenic factors including vascular endothelial growth factor (VEGF), fibroblast growth factor 2 (FGF2), interleukin 8 (IL-8) and angiogenin. Using quantitative real-time $\mathrm{PCR}$, we confirmed that a number of UPR inducing conditions (i.e., thapsigargin, tunicamycin, and no glucose) up-regulated VEGF, IL-8 and Angiogenin transcripts and extended these finding to a rat glioma line, a mouse fibroblast line and two human neuroblastoma lines. Our western blot and ELISA assay demonstrated the protein and secretion levels of VEGF were also elevated in C6 cells under ER stress condition.

To understand the mechanism by which ER stress triggers the up-regulation of pro-angiogenic factors, we tested the transcription rate and mRNA half-life of VEGF under ER stress condition. Both are dramatically increased by thapsigargin and glucose deprivation in $\mathrm{C} 6$ rat glioma cells. By chromatin IP experiments, we found that XBP1 bound to the promoter region of VEGF gene in response to ER stress in C6 cells which suggested that XBP1 may transactivate VEGF gene during UPR activation. After testing several stress inducible kinases which have been shown to contribute to stabilize VEGF mRNA in different cell lines in response to various stress conditions, we found that activation of both AMP-activating protein kinase (AMPK) and p38 mitogen activating protein kinase (p38 MAPK) elevate VEGF mRNA level by increasing its stability during ER stress. We also found that activation of JNK increase VEGF mRNA by increasing its transcription in response to the UPR. These results suggest that ER stress may increase the production of pro-angiogenic factors at multiple levels including increasing transcription of VEGF and stabilization of its mRNA, thus contributing to tumor angiogenesis.
\end{abstract}

\section{Document Type}

Thesis

\section{Degree Name}

Master of Science (MS)

\section{Program}

Molecular Sciences

\section{Research Advisor}

Linda M. Hendershot, Ph.D.

\section{Keywords}

tumor angiogenesis, the unfolded protein response, endoplasmic reticulum stress, pro-angiogenic factor, 
anti-angiogenic cancer therapy

\section{Subject Categories}

Medical Cell Biology | Medical Sciences | Medicine and Health Sciences 


\title{
THE UNFOLDED PROTEIN RESPONSE INCREASES PRODUCTION OF PRO-ANGIOGENIC FACTORS BY TUMOR CELL LINES
}

\author{
A Thesis \\ Presented for \\ The Graduate Studies Council \\ The University of Tennessee \\ Health Science Center
}

\author{
In Partial Fulfillment \\ Of the Requirements for the Degree \\ Master of Science \\ From The University of Tennessee
}

By

Nan Liao

May 2008 
Copyright $\odot 2007$ by Nan Liao

All rights reserved 


\section{DEDICATION}

The dissertation is dedicated to my parents

Mr. Zedong Liao

and

Mrs. Zhisong Ren

who have given me invaluable educational opportunities. 


\section{ACKNOWLEDGEMENTS}

I would like to thank Dr. Linda M. Hendershot, for her guidance, patience, and giving me the opportunity to learn from her and work in her laboratory. I would also like to thank my committee members, Dr. Ken Nishimoto and Dr. Clinton F. Stewart for taking time to assist in my research. Finally, I would like to thank everyone who has given me valuable help in my project throughout my last 5 years. 


\begin{abstract}
The rapid growth and proliferation of tumor cells will be limited at a stage when they encounter inadequate levels of oxygen and nutrient supply within the poorly vascularized tumor mass. These severe conditions negatively affect the proper folding of nascent proteins in the endoplasmic reticulum (ER) and lead to accumulation of unfolded protein within ER which is referred to as ER stress. Consequently, it will trigger the unfolded protein response (UPR) signal pathway through ER membrane stress sensor proteins including activating transcription factor 6 (ATF6), inositol-requiring 1 (IRE1) and PKR-like ER localized kinase (PERK). The UPR is largely a cytoprotective response and is thought to contribute to tumor survival in the face of inadequate nutrients and oxygen. Microarray analyses were conducted on Daoy, a human medulloblastoma line that was treated with thapsigargin, which activates the UPR by depleting $\mathrm{Ca} 2+$ from the ER. In addition to the expected UPR targets, we found that ER stress inducing agents led to the transcriptional induction of several pro-angiogenic factors including vascular endothelial growth factor (VEGF), fibroblast growth factor 2 (FGF2), interleukin 8 (IL-8) and angiogenin. Using quantitative real-time PCR, we confirmed that a number of UPR inducing conditions (i.e., thapsigargin, tunicamycin, and no glucose) up-regulated VEGF, IL-8 and Angiogenin transcripts and extended these finding to a rat glioma line, a mouse fibroblast line and two human neuroblastoma lines. Our western blot and ELISA assay demonstrated the protein and secretion levels of VEGF were also elevated in C6 cells under ER stress condition.
\end{abstract}

To understand the mechanism by which ER stress triggers the up-regulation of pro-angiogenic factors, we tested the transcription rate and mRNA half-life of VEGF under ER stress condition. Both are dramatically increased by thapsigargin and glucose deprivation in $\mathrm{C} 6$ rat glioma cells. By chromatin IP experiments, we found that XBP1 bound to the promoter region of VEGF gene in response to ER stress in C6 cells which suggested that XBP1 may transactivate VEGF gene during UPR activation. After testing several stress inducible kinases which have been shown to contribute to stabilize VEGF mRNA in different cell lines in response to various stress conditions, we found that activation of both AMP-activating protein kinase (AMPK) and p38 mitogen activating protein kinase (p38 MAPK) elevate VEGF mRNA level by increasing its stability during ER stress. We also found that activation of JNK increase VEGF mRNA by increasing its transcription in response to the UPR. These results suggest that ER stress may increase the production of pro-angiogenic factors at multiple levels including increasing transcription of VEGF and stabilization of its mRNA, thus contributing to tumor angiogenesis. 


\section{TABLE OF CONTENTS}

\section{Chapter 1. Introduction ........................................................................... 1}

ER Stress and the Unfolded Protein Response ....................................................... 1

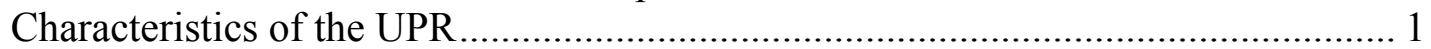

Components of the UPR Pathway........................................................................ 4

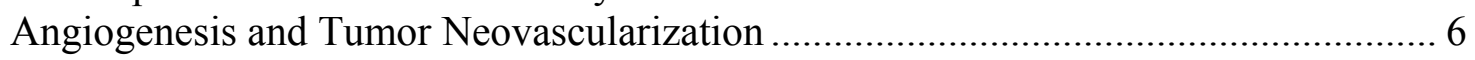

Angiogenesis in Development and Wound Healing Process.................................... 7

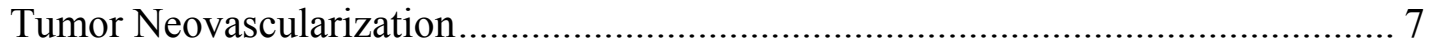

Contribution of the UPR to Tumor Progress ......................................................... 10

The UPR Is Activated in Solid Tumors of Both Human Patients and Transgenic

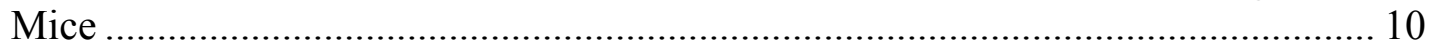

Tumor Establishment and Survival................................................................. 12

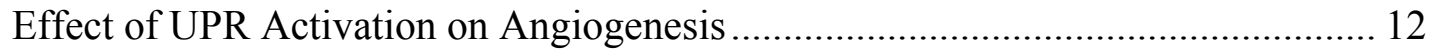

UPR Alters Sensitivity of Tumors to Chemotherapeutic Agents ........................... 13

Project Rationale and Significance ...................................................................... 13

Specific Aims ............................................................................................... 14

Aim 1. Characterize the Effect of UPR Activation on Regulating Pro-angiogenic

Factors in Different Tumor Cell Lines...................................................................... 14

Aim 2. Determine How the UPR Regulates the mRNA Levels of These Factors.... 14

\section{Chapter 2. The Unfolded Protein Response Increases Levels of Pro- angiogenic Factors in vitro ..................................................................................... 16}

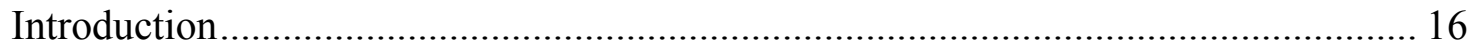

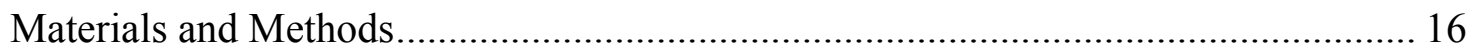

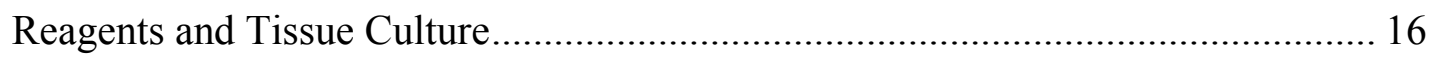

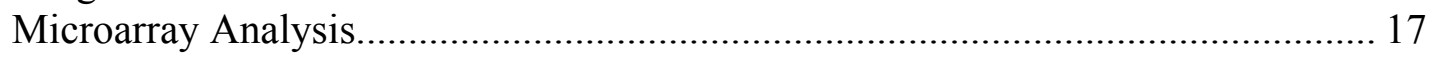

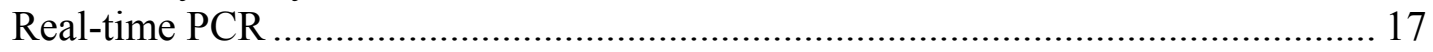

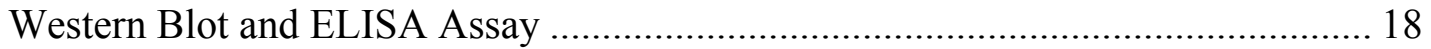

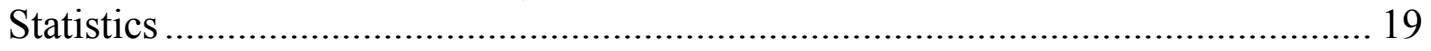

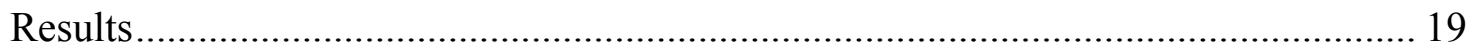

UPR Activation in Tumors of Transgenic Mouse Model and Human Patients....... 19

Up-regulation of Pro-angiogenic Factors by UPR Activation in vitro .................... 21

Mechanism of Increase of VEGF mRNA by UPR Activation ............................... 29

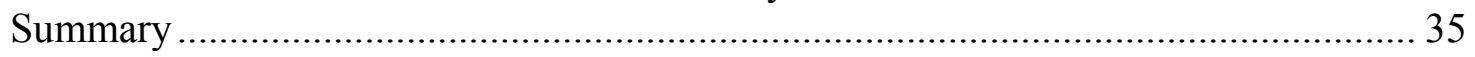

\section{Chapter 3. General Discussion ................................................................... 42}

Crosstalk of the UPR and the Hypoxia-induced Response.................................... 42

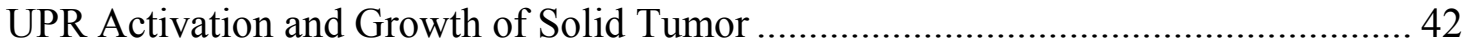

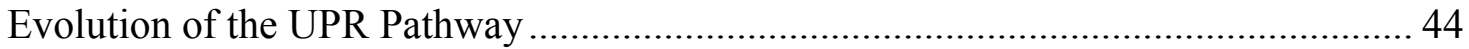

Implication of UPR Activation in Anti-angiogenic Cancer Therapy ......................... 45 
List of References ............................................................................. 47

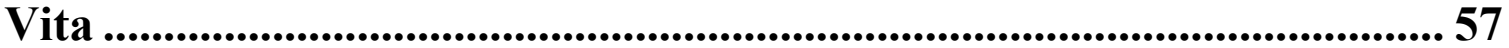




\section{LIST OF FIGURES}

Figure 1-1. ER stress and the unfolded protein response (UPR) ............................ 3

Figure 1-2. Components of the mammalian ER stress response .............................. 5

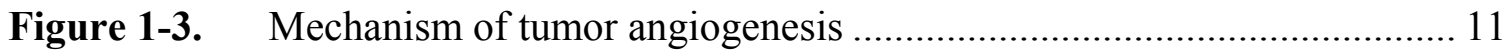

Figure 2-1. Evidence of UPR activation in tumors........................................... 20

Figure 2-2. Induction of UPR targets in different cell lines ............................... 23

Figure 2-3. Induction of VEGF in different cell lines ........................................ 24

Figure 2-4. Induction of Angiogenin in different cell lines .................................. 25

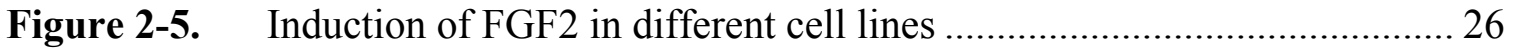

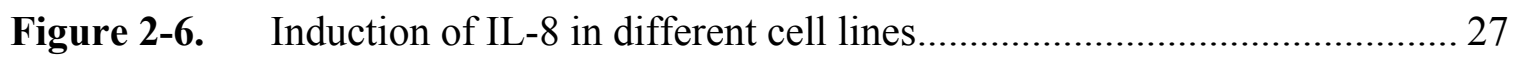

Figure 2-7. Induction of VEGF protein synthesis and secretion ........................... 28

Figure 2-8. Induction of VEGF mRNA under stresses..................................... 30

Figure 2-9. Decay of VEGF mRNA under stresses............................................ 31

Figure 2-10. VEGF is transcriptionally up-regulated in response to the UPR ............ 33

Figure 2-11. UPR activation does not significantly affect hnRNA splicing ............... 34

Figure 2-12. Potential binding sites of UPR downstream transcription factors in VEGF promoter ............................................................................. 36

Figure 2-13. AMPK and $\mathrm{p} 38$ MAPK increase VEGF mRNA in response to UPR activation by increasing its stability.

Figure 2-14. JNK increases VEGF mRNA in response to ER stress by increasing its transcription............................................................................... 38

Figure 2-15. PI3K and ERK do not increase VEGF in response to UPR activation .... 39

Figure 2-16. Model of UPR pathway regulating VEGF mRNA in C6 cells in vitro ... 41

Figure 3-1. Induction of Hif2 $\alpha$ under different stresses 43 


\section{LIST OF ABBREVIATIONS}

AMPK

ARE

ATF4

ATF6

BCL2

$\mathrm{BiP}$

CHOP

DTT

EDEM

eIF- $2 \alpha$

ELISA

ER

ERAD

ERdj3

ERdj4

ERK

ERSE

FBS

FGF2

GADD34

GRP94

GRP170

GSK3 $\beta$

$\mathrm{HAC} 1$

Hifl $\alpha$

Hif2 $\alpha$

hnRNA

IAP

IкB

IL-8

IRE1

JNK

MDM2

MEFs

NF- $\mathrm{KB}$

PCR

PDI

PDGF

PEDF

PERK

PI3K

PPIB

Ptch
AMP-activating protein kinase

AU-rich element

activating transcription factor 4

activating transcription factor 6

B-cell leukemia 2

immunoglobulin heavy chain-binding protein

C/EBP-homologous protein

dithiothreitol

ER degradation enhancing alpha-mannosidase-like protein

elongation initiation factor $2 \alpha$

enzyme-linked immunosorbent assay

endoplasmic reticulum

ER-associated degradation

ER DNA $j 3$

ER DNA j4

extracellular signal-regulated kinases

ER stress regulated element

fetal bovine serum

fibroblast growth factor 2

growth arrest and DNA damage gene 34

glucose regulated protein 94

glucose regulated protein 170

glycogen synthase kinase- $3 \beta$

homologous to ATF/CREB 1

hypoxia inducible factor $1 \alpha$

hypoxia inducible factor $2 \alpha$

heterogeneous nuclear RNA

inhibitor of apoptosis protein

inhibitor $\mathrm{\kappa B}$

interleukin 8

inositol-requiring 1

c-Jun N-terminal kinase

mouse double minute 2 homolog

mouse embryonic fibroblasts

nuclear factor $\mathrm{\kappa B}$

polymerase chain reaction

protein disulfide isomerase

platelet derived growth factor

pigment epirghelium dirived factor

PKR-like ER localized kinase

phosphatidylinositol 3-kinase

peptidyl-prolyl isomerase B

patched-like gene 


$\begin{array}{ll}\text { p38 MAPK } & \text { p38 mitogen activating protein kinase } \\ \text { topo II } & \text { topoisomerase II } \\ \text { UPR } & \text { unfolded protein response } \\ \text { UPRE } & \text { unfolded protein response regulated element } \\ \text { VEGF } & \text { vascular endothelial growth factor } \\ \text { XBP-1 } & \text { x box binding protein 1 } \\ \text { 2-DG } & \text { 2-deoxyglucose }\end{array}$




\section{Chapter 1. Introduction}

\section{ER Stress and the Unfolded Protein Response}

The endoplasmic reticulum (ER) regulates the synthesis and processing of nearly all proteins that reside in, or pass through, the endomembrane system of a eukaryotic cell (Hampton, 2000). This large group of proteins is delivered into the ER co-translationally or post-translationally and get modified and properly folded by ER resident enzymes and chaperons. Peptides that fail to fold correctly can be recognized and destroyed through ER-associated degradation (ERAD). The unfolded protein response (UPR) is a multifaceted signal transduction pathway that is activated in all eukaryotic organisms in response to changes in the environment of the endoplasmic reticulum (ER) that adversely affect protein folding and assembly in the secretory pathway (ER stress). The response is generally thought to protect cells from the transient alterations that can occur in the ER environment and serves to restore homeostasis in this organelle. Under extreme or prolonged stress, apoptotic pathways can be activated to destroy the cell. Recent studies reveal that in addition to protecting cells from adverse physiological conditions, the UPR plays an essential role in the development and normal functioning of some tissues and can be a major contributor to the pathology of some diseases.

\section{Characteristics of the UPR}

In 1977, GRP78 and GRP94 were first discovered as transformation-related proteins that were later demonstrated to be up-regulated by glucose deprivation and rapid metabolism (Pouyssegur et al., 1977; Shiu et al., 1977). Later, these two proteins were independently identified as ER resident chaperones, which monitor and help the folding and assembly of secreted and membrane-bound proteins (Bole et al., 1986; Hendershot et al., 1988; Lee, 1992). The concept of the UPR pathway was originally described in late 1980 s and early 1990s when the mammalian cells were found to respond to severe ER conditions, such as altered $\mathrm{pH}$, low levels of glucose or oxygen, or alterations in the oxidizing state of the ER by up-regulating the resident ER molecular chaperones. All these conditions perturb the normal folding and maturation of the secretory pathway proteins in this organelle, and indeed the entire UPR pathway can be activated by simply expressing a mutant protein that cannot fold properly in the ER (Kozutsumi et al., 1988). While this signal transduction pathway is primarily designed to safeguard the ER, its effects are extended to other organelles, and in extreme cases it protects the organism by terminating cells experiencing acute or chronic ER stress (Ma and Hendershot, 2004; Xu et al., 2005).

A number of changes in the normal ER environment can affect the folding of newly synthesized protein. For instance, lowering the ER pH alters side chain charges on polypeptides; glucose deprivation both interferes with the glycosylation of nascent proteins and inhibits energy production; and decreased oxygen causes the ER environment to become more reducing, which blocks the formation of disulfide bonds. 
When these post-translational modifications are inhibited, the nascent peptides cannot achieve their correct mature conformation and the incompletely folded proteins accumulate in the ER by quality control programs that prevent them from further transport along the secretory pathway (Ellgaard and Helenius, 2003). A number of pharmacological agents are routinely used to activate the UPR for experimental purposes (Lee, 1992). For example, thapsigargin, an inhibitor of the ER $\mathrm{Ca}^{2+}$ ATPase, depletes ER calcium, and tunicamycin prevents the addition of N-linked glycans to nascent ER proteins. DTT and 2- $\beta$ mercaptoethanol alter the oxidizing environment of the ER and interfere with formation of disulfide bonds that normally stabilize the folding and assembly of secretory pathway proteins, and 2-deoxyglucose (2-DG) mimics low glucose conditions by competing with glucose and prevents both N-linked glycosylation and energy production, which is required for protein folding (Helenius, 1994; Kornfeld and Kornfeld, 1985). Finally, Brefeldin A, an inhibitor of intracellular protein transport, causes proteins to accumulate in the ER and activate the UPR.

The UPR is thought to function primarily as a cytoprotective response that protects cells from transient but frequent changes in their environment (Figure 1-1). The hallmark of the response is the up-regulation of ER chaperones, which bind to unfolded regions on proteins, act to prevent their aggregation and promote proper refolding if stress conditions are alleviated. This aspect of the response is conserved in all organisms. A second feature of UPR activation is a transient inhibition of protein synthesis (Brostrom et al., 1996), which limits the load of unfolded proteins. Interestingly, the block in protein translation is not specific to ER proteins and occurs in all metazoans. A third component of the UPR is the expansion of the degradative capacity of the cell, which allows for the disposal of unfolded proteins (Brodsky et al., 1999; Kostova and Wolf, 2003) and is found in all eukaryotic organisms. ER-associated degradation (ERAD) is a highly selective mechanism used for both regulated degradation of certain functional ER resident proteins and for the removal of aberrant and unassembled proteins from the ER. Another long recognized aspect of the UPR is the arrest of cells in the G1 phase of cell cycle (Lee et al., 1986), which serves to protect the organism by inhibiting the proliferation of cells that are experiencing stress. Finally, if ER stress persists or is particularly severe, apoptotic pathways are initiated to eliminate the stressed cell. The first three functions contribute to preventing the aggregation of unfolded proteins by both limiting the load of unfolded proteins in the ER and increasing the concentration of molecular chaperones to deal with existing proteins. They constitute the cytoprotective functions of the UPR, whereas the arrest of cells in the G1 phase is considered to be both protective to the cell and the organism. Activation of apoptosis hits the point where the cytoprotective aspects of the response shift to cytodestructive ones in order to protect the organism. Thus, the entire response can be considered a protective one that is first active at the cellular level and later shifts to the organismal level. Where this threshold is set is not currently well understood and appears to vary between cell types. 


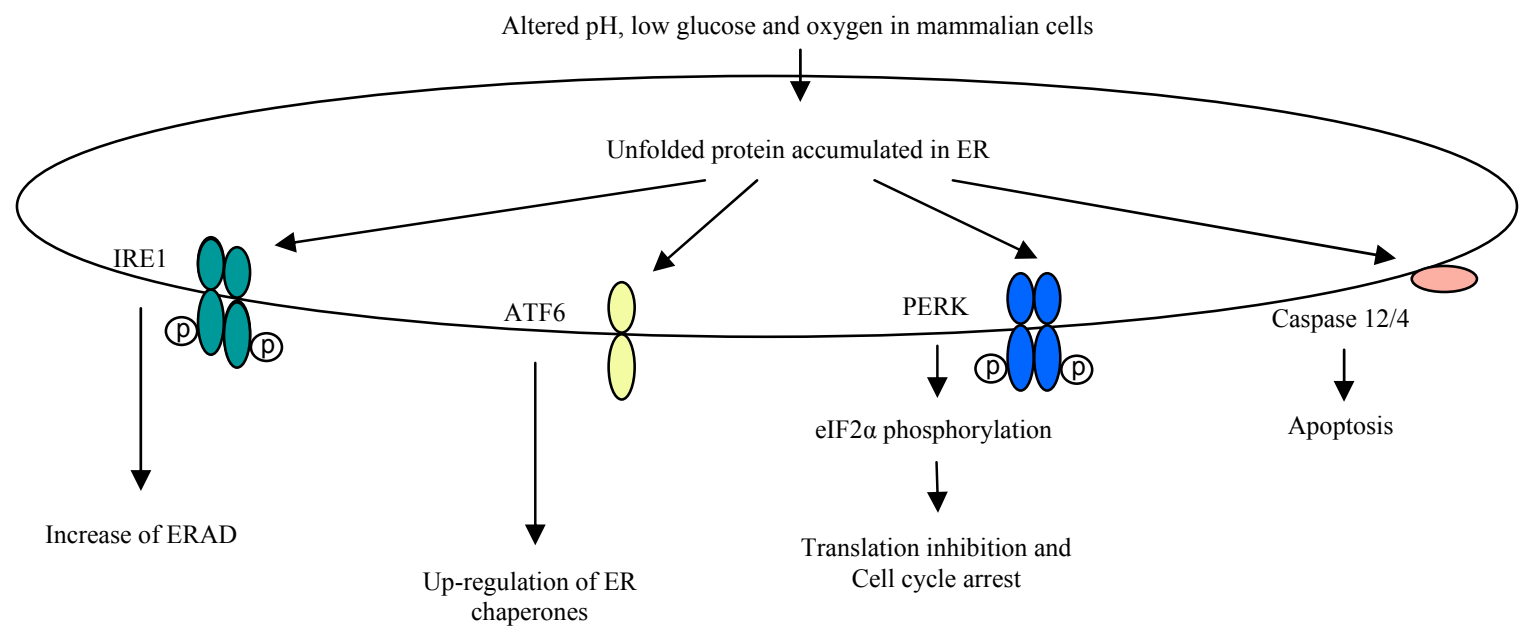

Figure 1-1. ER stress and the unfolded protein response (UPR). ER localized UPR transducers and the downstream responses they control. Four ER localized proteins have been identified that monitor evidence of stress conditions in the ER lumen and upon activation regulate the downstream responses. These include PERK (blue), an eIF-2 $\alpha$ kinase that is responsible for the transient inhibition of protein synthesis and cell cycle arrest. There are two Ire1 homologues (green), Ire1 $\alpha$ which is ubiquitously expressed and Ire $1 \beta$ which is expressed in the gut epithelium. Activation of Ire1 leads to cleavage of XBP-1, which in turn regulates components of the degradative machinery. The third transducer is ATF6 (yellow), which up-regulates ER chaperones, and the fourth stress sensor is caspase 12 in mouse and caspase 4 in human (pink), which activates apoptotic programs. 


\section{Components of the UPR Pathway}

The UPR response occurs in all known eukaryotes. It was first delineated in yeast which has a single ER stress transducer that activates the entire pathway. This pathway is conserved in higher eukaryotes but is largely expanded.

To identify the components of the UPR pathway in yeast, a 22-bp cis-acting element from BiP promoter (UPRE) was identified that was sufficient to confer ER stress-induced regulation of a heterologous transcript (Mori et al., 1992). This element was used in a genetic screen that led to the identification of Ire1 (Cox et al., 1993; Mori et al., 1993), which was originally discovered as inositol-requiring gene 1 (Ire1). The structure of Ire1 includes an N-terminal ER targeting sequence, a luminal "stresssensing" domain, a transmembrane domain, a cytosolic kinase domain, and a C-terminal domain that possesses endonuclease activity (Sidrauski and Walter, 1997). Ire1 is required for yeast survival during ER stress but not during normal cell growth (Cox et al., 1993; Mori et al., 1993). The target of Ire1's endonuclease activity is the HAC1 transcript, which encodes a basic leucine zipper transcription factor (Cox and Walter, 1996). HAC1 mRNA is constitutively expressed but not translated due to the presence of a 252nucleotide intron that inhibits translation. Activated Irelp cleaves the HAC1 transcript at either end of the intron and Rlg1p, a tRNA ligase, re-ligates the transcript in a spliceosome-independent reaction (Sidrauski et al., 1996). The spliced HAC1 mRNA is efficiently translated to produce Haclp, a transcription factor that translocates to the nucleus where it binds to UPREs in ER chaperone promoters and up-regulates these and numerous other UPR targets (Travers et al., 2000).

Mammals have preserved the basic components of the yeast UPR and greatly expanded it (Figure 1-2). Two Ire1 homologues exist in mammalian cells: IRE1 $\alpha$ and IRE1 $\beta$, which possess the same functions as yeast Ire1p (Tirasophon et al., 1998; Wang et al., 1998b). The only known target of Ire1's endonuclease activity is the X-box protein 1 (XBP-1) transcript (Calfon et al., 2002; Yoshida et al., 2001), which encodes a protein with a DNA binding domain but no transactivation domain in unspliced form. The excision of 26 bases from the XBP-1 transcript by activated Ire 1 changes the reading frame of the C-terminus of XBP-1, and the spliced form of XBP-1 now encodes a protein (XBP-1(S)) that has both a DNA binding domain and a transactivation domain (Calfon et al., 2002; Yoshida et al., 2001). The remodeled XBP-1(S) regulates components of the ERAD pathway, like EDEM (Yoshida et al., 2003), co-factors of the ER chaperone BiP, including ERdj3 and ERdj4 (Lee et al., 2003), an regulator of PERK's kinase activity, p58IPK, which relieve misfolding protein in the ER (van et al., 2003; Yan et al., 2002), and components of lipid synthesis that play a role in the expansion of ER membranes during the differentiation of some secretory tissues (Sriburi et al., 2004).

Unlike yeast, in mammalian cells, a transient inhibition of protein synthesis occurs during the UPR, which is achieved by phosphorylating the eukaryotic translation initiation factor-2 $\alpha$ (eIF-2 $\alpha$ ) through the activation of PERK (Harding et al., 1999; Shi et al., 1998). This leads to the loss of cyclin D1 from cells (Brewer and Diehl, 2000), causing a G1 arrest that prevents the proliferation of cells experiencing ER stress. 


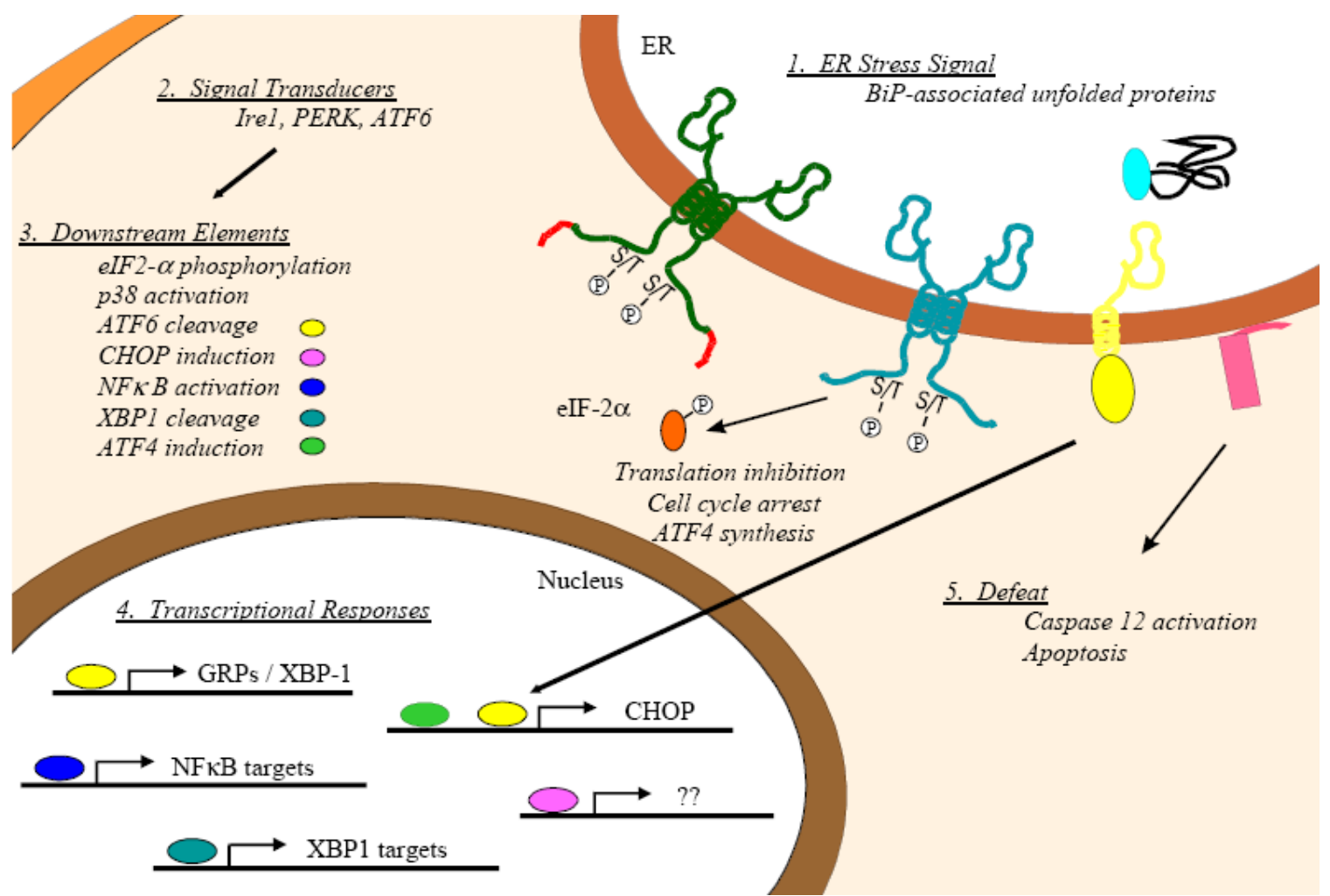

Figure 1-2. Components of the mammalian ER stress response. The accumulation of unfolded proteins in the ER leads to the activation of three ER membrane proteins Ire 1 (green), PERK (blue), and ATF6 (yellow) that act as signal transducers. These three arms of the response are largely cytoprotective and serve to regulate downstream targets which are ultimately responsible for the up-regulation of ER chaperones, inhibition of translation, cell cycle arrest, a number of other transcriptional responses including those downstream of ATF6 (yellow oval), AFT4 (green oval) NFאB (navy oval), and XBP-1 (blue oval). If the stress is not resolved, caspase 12 is activated to initiate apoptosis. (Adapted with permission from Liao, N. and Hendershot, L. M. (2007). The unfolded protein response: contributions to development and disease. Cell Stress Proteins 4, 57-88). 
Paradoxically, the translation inhibition specifically activates the expression of activating transcription factor 4 (ATF4), by suppressing the usage of several small open reading frames at the 5 end of the transcript that overlaps with the true ATF4 start site (Harding et al., 2000). ATF4 regulates a number of genes including those involved in metabolism and energy production (Harding et al., 2003; Siu et al., 2002). In addition, ATF4 plays a role in reversing the translation arrest by transactivating GADD34 (Ma and Hendershot, 2003; Novoa et al., 2001), the regulatory subunit of the PP1 phosphatase that dephosphorylates eIF-2 $\alpha$. This serves to reverse the translation arrest and contributes to apoptosis by inducing the C/EBP-homologous protein (CHOP) (McCullough et al., 2001; Zinszner et al., 1998). PERK is also required for NF- $\kappa B$ activation (Jiang et al., 2003), which upregulates anti-apoptotic proteins like BCL2 during ER stress. Thus, PERK sits at the crossroad of both survival and death signals.

Using a one-hybrid screen to identify proteins that bound to the ER stress regulated element (ERSE) found in ER chaperone promoters, Mori's group identified ATF6, a transcription factor that is synthesized as an ER-localized transmembrane protein, with a luminal stress sensing domain and a cytosolically oriented transcription factor domain (Haze et al., 1999). In response to ER stress, ATF6 is transported to the Golgi, where it is cleaved by the Golgi-localized S1P and S2P proteases (Ye et al., 2000), releasing the cytosolic transcription-factor domain. ATF6 up-regulates ER chaperones such as BiP, GRP94, and calreticulin, and folding enzymes like peptidyl-prolyl isomerase B (PPIase B) and protein disulfide isomerase (PDI) (Yoshida et al., 1998). ATF6 also serves to up-regulate the XBP-1 transcript (Yoshida et al., 2001).

If ER stress conditions are not resolved, apoptotic pathways are activated. In mouse, procaspase-12 is localized to the cytosolic face of the ER membrane and is activated in response to ER stress (Nakagawa et al., 2000) by IRE1-dependent mechanisms involving calpain activation (Nakagawa and Yuan, 2000). Although the human caspase-12 gene contains several missense mutations and clearly cannot have a role in UPR-induced apoptosis, recent data indicate that caspase-4 in humans is homologous to murine caspase-12 and is activated in an ER-stress-specific manner, indicating that it might be the human caspase-12 orthologue (Hitomi et al., 2004).

\section{Angiogenesis and Tumor Neovascularization}

Angiogenesis is a physiological process involving the growth of new blood vessels from pre-existing vessels which occurs in growth and development, as well as in wound healing process. During tumor progress, new blood vessel formation is critical to maintain the nutrient supply for a tumor to keep growing aggressively. Thus, it is a critical step in the transition of tumors from a dormant state to a malignant state which was first described as "tumor angiogenic switch" by Dr. Judah Folkman in 1971. 


\section{Angiogenesis in Development and Wound Healing Process}

The adult vasculature is derived from a network of blood vessels that is initially created in the embryo by vasculogenesis, a process in which vessels are formed de novo from endothelial cell precursors termed angioblasts (Risau, 1997). During vasculogenesis, angioblasts proliferate and construct a primitive network of vessels known as the primary capillary plexus. The endothelial cell lattice created by vasculogenesis then serves as a scaffold for angiogenesis (Papetti and Herman, 2002). After the primary capillary plexus is formed, it is remodeled by the sprouting and branching of new vessels from preexisting ones in the process of angiogenesis.

Most normal angiogenesis occurs in the embryo, where it establishes the primary vascular system as well as an adequate vasculature for growing and developing organs (Folkman, 1995). Angiogenesis occurs in the adult during the ovarian cycle and in physiological repair processes such as wound healing (Klagsbrun and D'Amore, 1991). Maturation and remodeling of newly formed microvessels is accomplished by the coordination of several diverse processes in the microvasculature (Klagsbrun and Moses, 1999). Angiogenesis is initiated by an increased permeability of existing blood vessel by removing pericytes from the branching vessel and degrading the basement membrane and extracellular matrix of endothelial cells. The new matrix synthesized by stromal cells, coupled with soluble growth factors, then promotes the migration and proliferation of endothelial cells. After sufficient proliferation, the endothelial cells arrest in a monolayer and form a tubelike structure. Pericytes and smooth muscles cells then are recruited to the surface of the endothelium and vessel is uncovered by pericytes regression. Blood flow is then established in the new vessel. The process is tightly controlled by a delicate balance of pro- and anti-angiogenic factors (Table 1-1).

\section{Tumor Neovascularization}

In tumor progression, neovascularization, also known as tumor angiogenesis is an essential step for cancer cells to overcome the limited blood supply and further proliferate themselves. Growth of solid tumors beyond $1-2 \mathrm{~mm}$ in diameter requires the induction and maintenance of a new blood supply. Failure to induce an angiogenic response may result in tumor 'dormancy' and interference with an established blood supply leads to necrosis or apoptosis of tumor cells and tumor regression (Folkman, 1996; Holmgren et al., 1995).

Under normal physiological condition, anti-angiogenic factors, also known as angiostatic factors, outweigh pro-angiogenic factors and angiogenesis does not occur. However, during tumor formation, pro-angiogenic factors are induced and highly expressed by tumor cells and their stromal partners. Their over-expression alters the balance and triggers the "angiogenic switch" of the tumor. Although a tumor may elicit the formation of blood vessels from preexisting capillaries in a process very similar to normal angiogenesis, tumor-induced blood vessels are structurally abnormal. Most of them lack functional pericytes (Benjamin et al., 1999) and have exceptional high 
Table 1-1. Major stimulators and inhibitors of angiogenesis.

\begin{tabular}{|c|c|c|c|}
\hline $\begin{array}{l}\text { Pro-angiogenic } \\
\text { factors }\end{array}$ & Biological functions & $\begin{array}{l}\text { Anti-angiogenic } \\
\text { factors }\end{array}$ & Biological functions \\
\hline VEGF family & $\begin{array}{c}\text { Permeability } \uparrow, \\
\text { Plasminogen activator } \\
\uparrow, \text { EC proliferation } \uparrow, \\
\text { EC apoptosis } \downarrow, \text { EC } \\
\text { migration, angiogenesis } \\
\text { in vivo }\end{array}$ & Angiostatin & $\begin{array}{c}\text { EC proliferation } \downarrow \text {, EC } \\
\text { apoptosis } \uparrow, \text { EC } \\
\text { migration } \downarrow \text {, tube } \\
\text { formation } \downarrow \text {, angiostatic } \\
\text { in vivo }\end{array}$ \\
\hline FGF family & $\begin{array}{c}\text { EC proliferation, } \\
\text { Plasminogen activator } \\
\uparrow, \text { EC migration, } \\
\text { angiogenesis in vivo }\end{array}$ & Endostatin & $\begin{array}{c}\text { EC proliferation } \downarrow, \text { EC } \\
\text { apoptosis } \uparrow, \text { EC } \\
\text { migration } \downarrow \text {, inhibition } \\
\text { of MMPs, angiostatic in } \\
\text { vivo }\end{array}$ \\
\hline Angiopoietin 1 & $\begin{array}{l}\text { EC sprouting, vessel } \\
\text { stabilization }\end{array}$ & Thrombospondin & $\begin{array}{c}\text { EC migration } \downarrow, \mathrm{EC} \\
\text { apoptosis } \uparrow \text {, angiostatic } \\
\text { in vivo }\end{array}$ \\
\hline Angiopoietin2 & $\begin{array}{l}\text { EC proliferation, EC } \\
\text { migration, EC sprouting } \\
\text { in presence of } V E G F\end{array}$ & $\begin{array}{c}\text { CXC } \\
\text { chemokines } \\
\text { without ELR } \\
\text { motif }\end{array}$ & $\begin{array}{l}\text { Inhibition of FGF and } \\
\text { VEGF165 bind to their } \\
\text { receptors, angiostatic in } \\
\text { vivo }\end{array}$ \\
\hline PDGF & $\begin{array}{l}\text { Chord formation in } \\
\text { vitro, proliferation of } \\
\text { SMC and PC, vessel } \\
\text { stabilization }\end{array}$ & PEDF & $\begin{array}{c}\text { EC migration } \downarrow, \mathrm{EC} \\
\text { apoptosis } \uparrow \text {, angiostatic } \\
\text { in vivo }\end{array}$ \\
\hline Angiogenin & EC proliferation & & \\
\hline
\end{tabular}

(Continued) 
Table 1-1 (continued).

\begin{tabular}{|c|c|c|c|}
\hline $\begin{array}{l}\text { Pro-angiogenic } \\
\text { factors }\end{array}$ & Biological functions & $\begin{array}{l}\text { Anti-angiogenic } \\
\text { factors }\end{array}$ & Biological functions \\
\hline $\begin{array}{l}\text { CXC chemokines } \\
\text { with ELR motif }\end{array}$ & $\begin{array}{l}\text { EC proliferation, } \\
\text { EC migration }\end{array}$ & & \\
\hline Integrins & $\begin{array}{c}\text { EC attachment, EC } \\
\text { migration, EC } \\
\text { apoptosis } \downarrow, \\
\text { essential for FGF } \\
\text { induced } \\
\text { angiogenesis }\end{array}$ & & \\
\hline
\end{tabular}

$\mathrm{EC}=$ endothelial cells; $\mathrm{SMC}=$ smooth muscle cells; $\mathrm{PC}=$ pericytes; $\mathrm{VEGF}=$ vascular endothelial growth factor; $\mathrm{FGF}=$ fibroblast growth factor; $\mathrm{PDGF}=$ platelet derived growth factor; $\mathrm{PEDF}=$ pigment epirghelium dirived factor 
permeability due to the presence of fenestrae and transcellular holes and lack of a complete basement membrane (Carmeliet et al., 1996). In addition, tumor vessel walls may be made up of both endothelial cells and tumor cells (Cheresh, 1987). These structural abnormalities in tumor vessels reflect the pathological nature of their induction, yet their ability to support cell growth also underlies the use of physiological mechanisms of angiogenesis that tumors commandeer for their propagation.

The induction of new blood vessel growth by a tumor is mediated through the action of many pro-angiogenic factors including VEGF, FGF2, IL-8, Angiopoietin2, Angiogenin. These factors are regularly expressed at a very low level. However, in tumor cells under hypoxia condition, they are highly induced. The mechanism by which a tumor induces neovasularization is shown in Figure 1-3.

\section{Contribution of the UPR to Tumor Progress}

\section{The UPR Is Activated in Solid Tumors of Both Human Patients and Transgenic Mice}

Once genotoxic alterations occur that essential to the development of a cancer cell, the tumor encounters an inadequate environment that can become growth limiting. These conditions lead to the activation of cytoprotective responses including the hypoxia induced response (Graeber et al., 1996; Hockel and Vaupel, 2001a; Hockel and Vaupel, 2001b)and the UPR (Feldman et al., 2005; Ma and Hendershot, 2004). Primary hepatocellular carcinomas show evidence of XBP-1 and ATF6 activation (Shuda et al., 2003), and downstream targets like CHOP, BiP, GRP94, and GRP170 (also known as ORP150) have been reported to be up-regulated in breast tumors (Fernandez et al., 2000), hepatocellular carcinomas (Shuda et al., 2003), gastric tumors (Song et al., 2001), and esophageal adenocarcinomas (Chen et al., 2002). One study reported that BiP was overexpressed more frequently in the higher-grade, estrogen-receptor-negative tumors than in lower-grade, estrogen-receptor-positive tumors (Fernandez et al., 2000), suggesting that UPR activation is correlated with a clinically more aggressive phenotype. In support of this, a fibrosarcoma cell line that was engineered to have lower levels of BiP formed tumors initially, but they were rapidly resolved (Jamora et al., 1996). In two more recent studies, researchers found that transformed PERK null MEFs produced much smaller tumors that exhibited higher levels of apoptosis in hypoxic areas than wild-type MEFs (Bi et al., 2005), and that XBP-1 null MEFs and XBP-1-knockdown cells did not form tumors in mice, even though their growth rate and secretion of VEGF were similar to wild-type cells (Romero-Ramirez et al., 2004). Since both PERK and XBP-1 activation are specific to the UPR pathway, this evidence suggests that not only is the UPR activated but that it can play an essential role in tumorigenesis. 
A

B

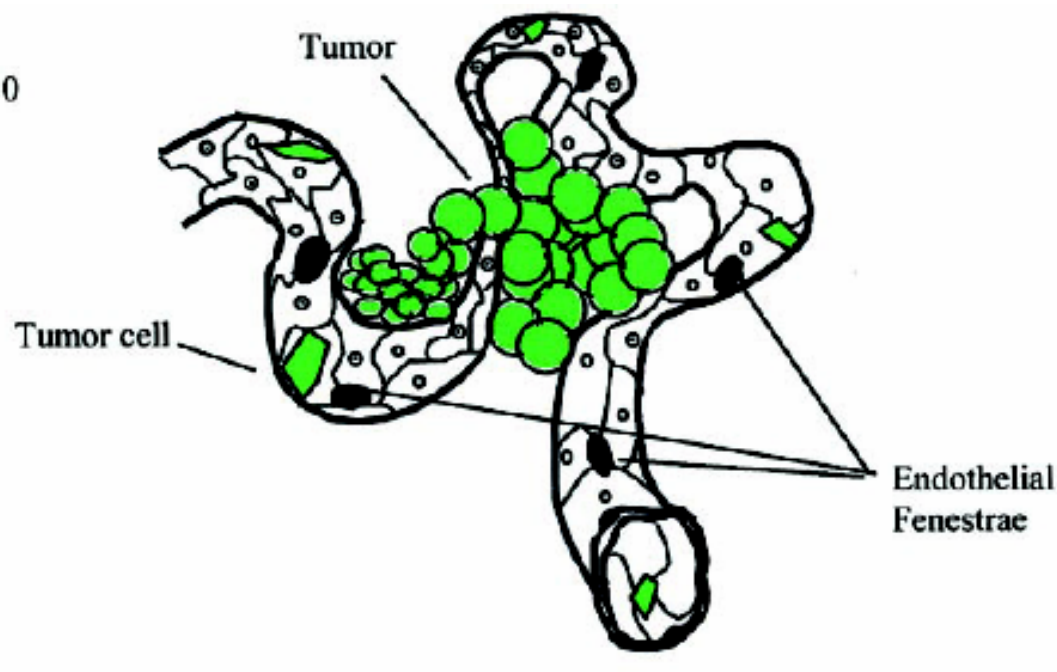

i.
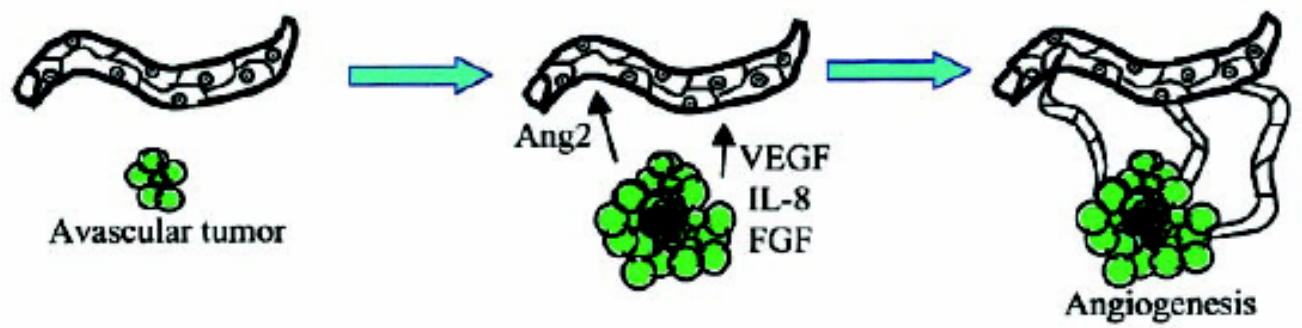

ii.

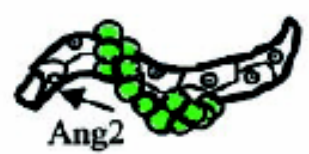

Vascularized tumor

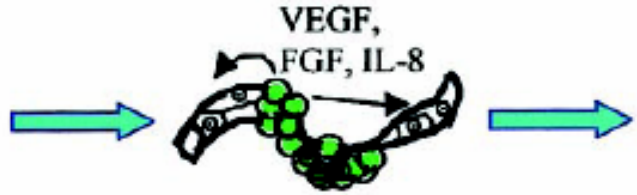

Vessel regression, tumor hypoxia

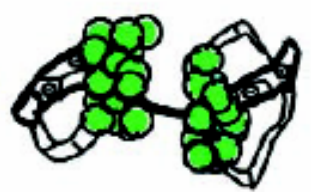

Angiogenesis

Figure 1-3. Mechanism of tumor angiogenesis. A: schematic of tumor blood vessel (green, normal tumor cells; black, necrotic tumor cells). Notice the thin walls, tortuous shape, absence of pericytes, and variations in diameter. Numerous gaps or fenestrae are found between endothelial cells. The vessel wall is mosaic and can consist of both tumor cells as well as endothelial cells. $B$ : model of tumor-induced neovascularization. In $i$, an initially avascular tumor grows until inner regions become hypoxic and upregulate production of angiogenic factors such as VEGF, FGF and interleukin (IL)-8. In ii, a tumor grows on an existing blood vessel. Soon the tumor induces Ang2 expression in the preexisting vessel, and it regresses due to endothelial cell apoptosis. The tumor is now avascular, and by upregulating angiogenic factors as in $i$, it induces the production of a new blood supply. (Reprinted with permission from Yancopoulos, G. D., Davis, S., Gale, N. W., Rudge, J. S., Wiegand, S. J., and Holash, J. (2000). Vascular-specific growth factors and blood vessel formation. Nature 407, 242-248.) 


\section{Tumor Establishment and Survival}

Many studies have focused on the signal transduction pathway activated in response to hypoxic conditions and demonstrated that hypoxia-inducible factor $1 \alpha(\operatorname{Hif} 1 \alpha)$ plays a critical role in tumor growth and angiogenesis (Pugh and Ratcliffe, 2003; Semenza et al., 2000). Several recent studies provide evidence to suggest that the UPR and Hifl $\alpha$ pathways are related to each other and may interact to regulate downstream targets. For instance, cells cultured under hypoxic conditions activated PERK (Koumenis et al., 2002), leading to eIF2 $\alpha$ phosphorylation and expression of both ATF4 and GADD34 (Blais et al., 2004), suggesting that this branch of UPR is fully activated by hypoxia. Hypoxia can also lead to activation of NFkB through a phosphorylationmediated degradation of IKB (Koong et al., 1994), and more recent studies have shown that ER stress activates NFkB through a PERK dependent loss of IкB (Jiang et al., 2003). Suggesting that multiple mechanisms for NFkB activation may be employed in a tumor cell, it represents a possible point of synergy in the activation of this important antiapoptotic protein. CHOP, a pro-apoptotic factor, is also up-regulated by PERK. It is presently unclear if these represent opposing effects on cell survival or if the dismantling of apoptotic machinery that is a common feature to the transformation process interferes with the $\mathrm{CHOP}$ effect in tumor cells. Indeed, a number of the pro-apoptotic components that are activated during ER stress converge on the caspase 3/9 pathway, which is often mutated or disabled in tumor cells (Soung et al., 2004), and the down-regulation of Bcl2 by CHOP maybe countered by the NFKB's activation of anti-apoptic factors like c-IAP1 and c-IAP2 (Wang et al., 1998a) or its suppression of targets like PTEN (Vasudevan et al., 2004).

Some targets are regulated differently by the two pathways. For example, the proapoptotic tumor suppressor p53 is stabilized in response to hypoxia through a reduction in the level of MDM2, which targets p53 for proteasomal degradation (Alarcon et al., 1999). However, during ER stress, glycogen synthase kinase-3 $\beta$ (GSK3 $\beta$ ) is activated and phosphorylates p53, which accelerates its degradation (Qu et al., 2004). As hypoxia condition can both induce the UPR due to inhibition of disulfide bond formation, and induce the classic hypoxia induced pathway through Hif $1 \alpha / 2 \alpha$, it is important to clarify which of these two pathways is dominant in cancer cells that retain p53 function and have activated both pathways.

\section{Effect of UPR Activation on Angiogenesis}

Tumors respond to their inadequate vascularization by secreting the proangiogenic factor, VEGF ((Ferrara and vis-Smyth, 1997). Recent studies demonstrate that in addition to its well characterized induction via Hifl $\alpha$ transactivation (Poellinger and Johnson, 2004; Semenza, 2001), VEGF is also up-regulated by the UPR through an ATF4-dependent pathway (Roybal et al., 2004). Furthermore, its processing in the ER and secretion is controlled by GRP170, an ER chaperone that is up-regulated during both ER stress (Lin et al., 1993) and hypoxia (Ikeda et al., 1997; Tamatani et al., 2001).

GRP170 increases the resistance of cells to hypoxia (Ozawa et al., 1999), and tumors 
cells that were manipulated to express high levels of GRP170 showed enhanced secretion of VEGF, whereas decreasing the amount of GRP170 led to ER retention of VEGF (Ozawa et al., 2001). When these cells were used in xenograft studies, the tumors expressing low levels of GRP170 grew very poorly in animals, whereas cells that overexpressed GRP170 produced larger tumors than the parental line (Ozawa et al., 2001).

\section{UPR Alters Sensitivity of Tumors to Chemotherapeutic Agents}

In addition to a role in promoting tumor growth, there are a number of studies to suggest that UPR activation in tumors might alter their sensitivity to chemotherapy. The in vitro treatment of cultured cells with drugs that activate the UPR increases their resistance to topoisomerase II (topo II) poisons (Hughes et al., 1989), which is thought to occur via a UPR-mediated decrease in topo II levels (Gosky and Chatterjee, 2003; Shen et al., 1989; Yun et al., 1995). Other studies have shown that the increased levels of BiP that occur during UPR activation can result in the relocalization of $\mathrm{BiP}$ to the cytosol where it binds caspase 7 and caspase 12 and prevents their activation in response to some chemotherapeutic agents (Rao et al., 2002; Reddy et al., 2003). Activation of the UPR has also been shown to up-regulate P-glycoprotein (Ledoux et al., 2003), which induces multiple drug resistance. However, UPR activation can also increase the sensitivity of some tumors to DNA cross-linking agents, like cisplatin (Chatterjee et al., 1997; Yamada et al., 1999). A recent study reported that cisplatin is a potent UPR activator and induces a calpain-dependent activation of caspase-12 (Mandic et al., 2003). Changes in the level of any of the components of the DNA repair system in response to UPR activation could also contribute to the increased sensitivity to these agents, although there are currently no data to support this hypothesis. Together these studies suggest that it may be important to couple information on UPR activation in tumors with treatment choices.

\section{Project Rationale and Significance}

As increasing evidence showed UPR activation in various solid tumors, it is important to understand what role the UPR plays in tumor progression. In my initial microarray studies on a human medulloblastoma line treated with the UPR inducer thapsigargin, I observed that four pro-angiogenic factors - VEGF, IL-8, FGF2 and Angiogenin were up-regulated. This result leads us to further investigate the relation between UPR activation and the induction of angiogenesis in tumors. Two major aspects of the role of the UPR in the regulation of proangiogenic factors will be investigated. First, I will verify the microarray data and establish whether these genes are also induced by other agents that affect folding in the ER and determine if this occurs in other types of tumor cells. Second, I will determine the mechanism(s) leading to increased expression of these genes during UPR activation.

Knowledge of the role of the UPR in tumor neovascularization will facilitate our understanding of the effect of UPR activation in tumorigenesis. With the potential for 
designing inhibitors of oncogenic promoting factors in the UPR, it may be possible to use this information to increase the efficacy of available anti-angiogenic drugs and perhaps to design new ones.

\section{Specific Aims}

The main aim of this project is to address the role of the unfolded protein response (UPR) in regulating the expression of pro-angiogenic, with the long term goal being to determine to what extent the UPR contributes to angiogenesis. After a cancer cell arises from series of genotoxic alterations, the rapid growth and proliferation of tumor will be limited at a stage when it encounters inadequate levels of oxygen and nutrients within the poorly vascularized tumor mass. In cultured cells, these severe conditions lead to the activation of cellular stress responses including the UPR which is trigged by the physiological environment alteration of endoplasmic reticulum, a condition known as ER stress (Lee, 1992). Indeed, there are in vivo data to demonstrate that solid tumors can respond to their insufficient environment by activating at least some elements of the UPR. To resolve insufficient vascularization and re-gain the access to oxygen and nutrients, tumor cells and their stromal partners secrete pro-angiogenic factors which coordinately activate proliferation of endothelial cells and promote tumor angiogenesis. In our preliminary studies, we observed that four important pro-angiogenic factors VEGF, FGF2, IL-8 and Angiogenin - are up-regulated during UPR activation in several tumor cell lines. During the course of my studies, several publications reported VEGF and IL-8 are up-regulated by the UPR at both mRNA and secretion level. This implied that the UPR may play an important role in promoting tumor angiogenesis by regulating the levels of these pro-angiogenic factors during tumor progress. Therefore, based on these previous data, I addressed the following issues in the next chapter.

\section{Aim 1. Characterize the Effect of UPR Activation on Regulating Pro-angiogenic Factors in Different Tumor Cell Lines}

First, I will establish whether the up-regulation of transcripts of pro-angiogenic factors occurs in response to other UPR inducers and assess how the level of induction compares to that observed with hypoxia. Second, I will determine whether induction of these genes occurs in multiple cell types. And third, I will compare the magnitude of VEGF secretion in response to UPR activation versus hypoxia.

\section{Aim 2. Determine How the UPR Regulates the mRNA Levels of These Factors}

First, I will determine whether the increase of mRNA levels of VEGF factors are due to transcription activation or a result of increased mRNA stability. Second, I will determine which branch(es) and what downstream target(s) of the UPR are responsible for regulating the transcription. And third, I will determine which branch(es) and what 
downstream target(s) of the UPR are responsible for the increased stability of VEGF mRNA. 


\section{Chapter 2. The Unfolded Protein Response Increases Levels of Pro-angiogenic Factors in vitro}

\section{Introduction}

Recently, the UPR signal pathway has been shown to be activated in tumors of both human patients and mouse models. Therefore, it is important to understand how UPR activation affects tumor growth and response to therapeutic intervention. Many aspects of the UPR are cytoprotective, and several studies indicate that activation of the UPR may have a crucial role in tumor growth. However, prolonged activation of the response can initiate apoptosis, which could serve to protect the host. At present, it is unclear where this balance lies in tumor development. In addition, activation of the UPR in cell culture has been shown to alter the chemosensitivity of tumors, making them more sensitive to certain drugs and more resistant to others, again underscoring the fact that activation of the UPR can lead to contradictory consequences for tumors.

We started the project by testing the extent of the UPR in the Daoy medulloblastoma cell line which can be used in xenograft studies. Micro-array analysis demonstrated that the expected UPR downstream targets were up-regulated when cells were treated with the ER stress inducer thapsigargin, which poisons the ER calcium ATPase and rapidly depletes calcium from the ER, which is essential for the proper folding of many secretory pathway proteins. Unexpectedly, we also found that several pro-angiogenic factors such as VEGF, FGF2, IL-8 and Angiogenin were also increased by ER stress treatment. Through real-time PCR assay, I verified the induction of these pro-angiogenic factors in Daoy cells and extended these findings to other tumor cell lines. In addition, Western Blot and ELISA assays showed that the secretion of VEGF protein was also increased dramatically during ER stress to levels even higher than those observed with hypoxia. In this chapter, I will describe how I conducted the experiments to test the increase of pro-angiogenic factors by the UPR and what has been done to investigate the mechanism by which the UPR increase VEGF mRNA level in vitro.

\section{Materials and Methods}

\section{Reagents and Tissue Culture}

Actinomycin D (Act. D), LY294002, PD98059, SB203580, SP600580, cobalt chloride $\left(\mathrm{CoCl}_{2}\right)$, tunicamycin $(\mathrm{Tm})$ and thapsigargin $(\mathrm{Tg})$ were purchased from SigmaAldrich. Compound $\mathrm{C}$ was obtained from Cell Signaling Technology. DMEM and RPMI media, both with and without glucose came from Invitrogen.

NIH3T3 mouse fibroblast cells, C6 rat glioma cells and Daoy human medulloblastoma cells were cultured in DMEM supplemented with $10 \%$ heat-inactivated 
fetal bovine serum (FBS) at $37^{\circ} \mathrm{C}$ with $95 \%$ air and $5 \% \mathrm{CO}_{2}$. NB- 1691 and SK-N-AS human neuroblastoma cell lines were regularly cultured in RPMI supplemented with $10 \%$ heat-inactivated $\mathrm{FBS}$ at $37^{\circ} \mathrm{C}$ with $95 \%$ air and $5 \% \mathrm{CO}_{2}$. As a more physiological method of activating the UPR, cells were cultured in glucose-free DMEM or RPMI supplemented with $10 \%$ heat-inactivated and dialyzed $\mathrm{FBS}$ at $37^{\circ} \mathrm{C}$ with $95 \%$ air and $5 \% \mathrm{CO}_{2}$. Hypoxic responses were induced by culturing cells in the same regular media at $37^{\circ} \mathrm{C}$ with $94 \%$ nitrogen, $1 \% \mathrm{O}_{2}$ and $5 \% \mathrm{CO}_{2}$.

\section{Microarray Analysis}

Total RNA isolated using RNeasy kits (Qiagen) was prepared for hybridization to Affymetrix HG-U133Plus2 chips following the Affymetrix one-cycle labeling protocol (http://www.affymetrix.com/support/technical/manual/expression_manual.affx). After purification, the cDNA was used as template to incorporate biotin-label into anti-sense cRNA by using the T7 RNA polymerase and biotin-labeled nucleotide. Fifteen micrograms of the biotin-labeled cRNA were fragmented by heating and metal induced hydrolysis, added to a hybridization cocktail containing probe array controls and blocking agents (BSA and herring sperm DNA), then incubated overnight at $45^{\circ} \mathrm{C}$ on a GeneChip array. Following hybridization, the arrays were automatically washed in a GeneChip Fluidics Station 450 using high stringency conditions to remove non-hybridized labeled cRNA. Experiments were done in duplicate. Expression signals for each probeset were calculated using the Affymetrix GeneChip Operating Software (GCOS version 1.4). Relative fold change of each gene was calculated by normalizing data from the thapsigargin treated group to the control experimental condition. Mean value was obtained from duplicated experiments.

\section{Real-time PCR}

Quantitative real-time PCR experiments were performed on the HT7900 Sequence Detection System (Applied Biosystems) with 40 amplification cycles. Quantitative data were obtained using a standard curve method. Total RNA was extracted from cells by using Quiagen RNAeasy Mini Kit. TaqMan® One-Step RT-PCR Master Mix Reagents (from Applied Biosystems) were used to conduct the real-time PCR reactions in 96-well plates. Commercial 18s rRNA primers/probe were used as the internal control for all real-time PCR experiments. The following primers/probes were used for individual target genes:

$\mathrm{BiP}$ (rat or mouse) forward primer, AGGAGACTGCTGAGGCGTAT; BiP (rat or mouse) reverse primer, GCTGGGCATCATTGAAGTAA; BiP (human, rat or mouse) probe, CTGCATGGGTAACCTTCTTTCCCAA. BiP (human) forward primer, CTCAACATGGATCTGTTCCG; BiP (human) reverse primer, CCAGTTGCTGAATCTTTGGA; BiP (human) probe, TTCGAGTCGAGCCACCAACAAGA. CHOP (rat or mouse) forward primer, GCGACAGAGCCAGAATAACA; CHOP (rat or mouse) reverse primer, 
ACCAGGTTCTGCTTTCAGGT; CHOP (rat or mouse) probe, AACACTCTCTCCTCAGGTTCCGGC. CHOP (human) forward primer, TCCTGGAAATGAAGAGGAAGA; CHOP (human) reverse primer, CAGGGAGCTCTGACTGGAAT; CHOP (human) probe, CACAAGCACCTCCCAGAGCCC. GRP170 (rat or mouse) forward primer, GACAGGGTGGAGTCCGTATT; GRP170 (rat or mouse) reverse primer, CAAACAGGCTGGATATGGTG; GRP170 (rat or mouse) probe, TCTGGGCTATCCTCCACCAGGG. GRP170 (human) forward primer, TTGGGCATGGTTCTCAATTA; GRP170 (human) reverse primer, CTGGTTGAAGAAGACTGGCA; GRP170 (human) probe, TGCAGAGCAGCCCATCAAGGA. Angiogenin (rat) forward primer, GCAAGCATACAGGAGGGTCT; Angiogenin (rat) reverse primer, CATCAAAGTGGACAGGCAAG; Angiogenin (rat) probe, CCTTGCCGGTACCGAGCCTC. Angiogenin (mouse) forward primer, GCCAGCTTTGGAATCTCTGT; Angiogenin (mouse) reverse primer, AGAGTGGGAGGGATCACAAC; Angiogenin (mouse) probe, CGATAAGCCCAGGCCCGTTG. Angiogenin (human) forward primer, AGGAGCCTGTGTTGGAAGAG; Angiogenin (human) reverse primer, AGCACGAAGACCAACAACAA; Anigiogenin (human) probe, AACGCCCAGGCCCATCACC. FGF2 (rat or mouse) forward primer, GCTGCTGGCTTCTAAGTGTG; FGF2 (rat or mouse) reverse primer, TACTGCCCAGTTCGTTTCAG; FGF2 (rat or mouse) probe, ACCAACTGGAGTATTTCCGTGACCG. FGF2 (human) forward primer, TGGCTATGAAGGAAGATGGA; FGF2 (human) reverse primer, ACTGCCCAGTTCGTTTCAGT; FGF2 (human) probe, CCAACTGGTGTATTTCCTTGACCGG. IL-8 (human) forward primer, AGGACAAGAGCCAGGAAGAA; IL-8 (human) reverse primer, ACTGCACCTTCACACAGAGC; IL-8 (human) probe, ACTTCCAAGCTGGCCGTGGC. VEGF (rat or mouse) forward primer, CACTGGACCCTGGCTTTACT; VEGF (rat or mouse) reverse primer, CTTCTGTCGTGGGTGCAG; VEGF (rat or mouse) probe, CCATGCCAAGTGGTCCCAGG. VEGF (human) forward primer, AGAAGGAGGAGGGCAGAATC; VEGF (human) reverse primer, TCTCGATTGGATGGCAGTAG; VEGF (human) probe, CATCCATGAACTTCACCACTTCGTGA. VEGF hnRNA (rat) forward primer, AAGGTGAGTCCTCATGCTTGT; VEGF hnRNA (rat) reverse primer, GTGCAATCTCGACCCTCATA; VEGF hnRNA (rat) probe, TGGGTCCCTGTTGTCCCATTCC.

\section{Western Blot and ELISA Assay}

For Western Blot assay, cells were trypsinized for 5 minutes at $37^{\circ} \mathrm{C}$. Complete DMEM or RPMI with $10 \%$ FBS was used to inactivate trypsin at room temperature. Cell pellets were centrifuged down, washed twice with cold PBS and stored in $-80^{\circ} \mathrm{C}$ until needed. Whole cell lysates were obtained by lysing cell pellets in RIPA cell lysis buffer 
(50 mM Tris- $\mathrm{HCl}$ (pH7.4), $150 \mathrm{mM} \mathrm{NaCl}, 1 \mathrm{mM}$ PMSF, $1 \mathrm{mM}$ EDTA, $5 \mu \mathrm{g} / \mathrm{ml}$ Aprotinin, $5 \mu \mathrm{g} / \mathrm{ml}$ Leupeptin, $1 \%$ Triton X-100, $1 \%$ sodium deoxycholate and $0.1 \%$ SDS) at $4^{\circ} \mathrm{C}$ for 15 minutes. Cell lysates were clarified by centrifugation at $14,000 \mathrm{rpm}$ for 30 minutes. After adding an equal volume of $2 \mathrm{X}$ of SDS reducing sample buffer $(62.5 \mathrm{mM}$ Tris- $\mathrm{HCl}$ (pH 6.8), 10\% glycerol, 5\% b-mercaptoethanol, 2\% SDS), samples were denatured by heating at $90^{\circ} \mathrm{C}$ for 10 minutes. Proteins were separated by reducing SDS$10 \%$ acrylamide gels, transferred to a PVDF membrane and probed with the indicated primary antibody: Polyclonal rabbit-anti-BiP, anti-GRP170 and anti-CHOP antisera were raised against hamster recombinant $\mathrm{BiP}$, an $\mathrm{N}$-terminal fagment of human recombinant GRP170 or mouse recombinant CHOP respectively and have been described previously. Polyclonal rabbit-anti-VEGF antisera was purchased from R\&D systems.

VEGF ELISA assays were performed using a commercial kits specific for rat VEGF (R\&D Systems). Assays for each sample were performed in duplicate, and readings were compared with standard curves obtained with the rat recombinant VEGF165 that was provided.

\section{Statistics}

All real-time PCR experiments were performed in either duplicate or triplicate as indicated in figure legends. Means and standard deviations of each sample were calculated by Microsoft Excel. Data were normalized to the relative fold change comparing to control sample. VEGF ELISA assay was performed in triplicate. Means and standard deviations of each sample were calculated by Microsoft Excel.

\section{Results}

\section{UPR Activation in Tumors of Transgenic Mouse Model and Human Patients}

To investigate whether the UPR was induced in a genetic tumor model for medulloblastoma, our lab performed in situ hybridization analysis on the slides of brain tumors which spontaneously arise from Ptch + - p18-/- transgenic mice. For expression of BiP (downstream of ATF6), CHOP (downstream of PERK) and ERdj4 (downstream of Ire1/XBP-1), we found that all three UPR target genes were induced, which demonstrate that the UPR is activated in these solid tumors. In the mean time, an immunohistochemistry analysis was done on human neuroblastoma patient samples. We found evidence of $\mathrm{CHOP}$ expression in a number of samples from various tumor types, including those from neuroblastomas (Figure 2-1), which indicates that at least the PERK branch of the UPR is activated. 
A.

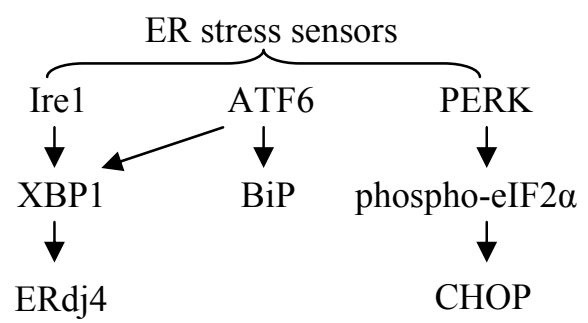

C.

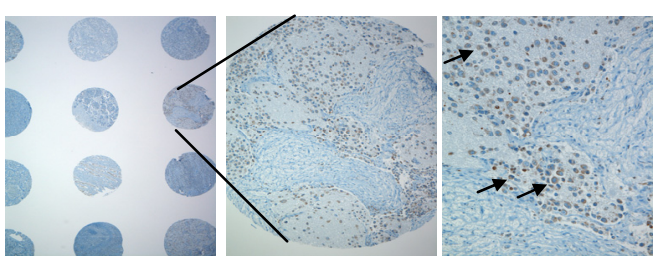

B.
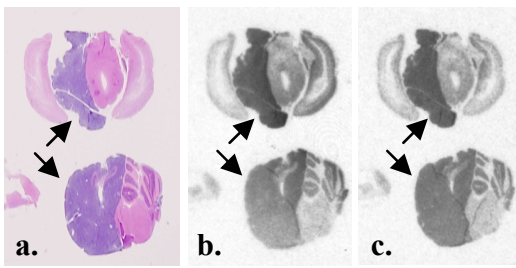

c.

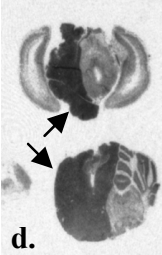

D.

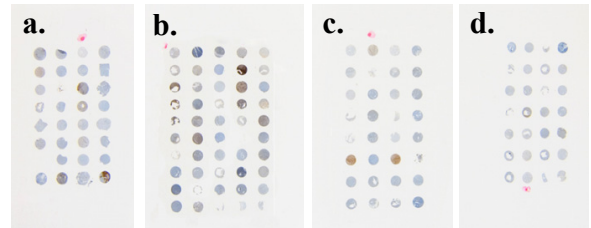

Figure 2-1. Evidence of UPR activation in tumors. (A) Schematic of the three branches of the UPR and a downstream target of each. (B) The brain of a Ptc1+/-, p18-/- mouse that had developed a medulloblastoma was isolated, separated into the cerebrum (top) and cerebellum (bottom), and fixed. After sectioning, tissue slices were stained with $\mathrm{H} \& \mathrm{E}$ (a) or hybridized with probes for BiP (b), CHOP (c), or ERdj4 (d). Areas of obvious tumor growth are indicated with arrows. (C) Slides from the human tumor tissue array were stained with anti-CHOP. A portion of one slide containing a neuroblastoma is expanded at two magnifications. The arrows identify the neuroblastoma cells in the tissue core. ( D) Four different slides (right) representing xenografts of rhabdomyosarcomas (a), brain tumors (b), Wilm's and kidney tumors (c), and osteosarcomas (d) were stained with anti-CHOP to detect UPR activation. 


\section{Up-regulation of Pro-angiogenic Factors by UPR Activation in vitro}

Since there is increasing evidence to show that at least some aspects of the UPR are activated in solid tumors, we wished to more carefully examine this in xenograft studies. We initially chose the Daoy human medulloblastoma for our studies and wished to establish that this line maintained the ability to mount a full UPR in response to conventional chemical UPR inducers. Daoy cells were treated with or without thapsigargin which induces the UPR by depleting $\mathrm{Ca}^{2+}$ from ER and mRNA from these cells were subjected to microarray analysis. We found that indeed all known targets of the UPR were induced and that these represented downstream targets of all three transducers (Table 2-1). Unexpectedly, we also observed several pro-angiogenic factors were induced by thapsigargin treatment (Table 2-1). To further confirm these findings, extend them to other UPR inducing agents, and compare the levels of induction to those obtained with hypoxia, real-time PCR analyses were used to determine the mRNA levels of these factors in the Daoy cell line as well as in several other tumor lines that are routinely used in xenograft studies and a non-tumor line that has been extensively used to study the UPR. These included the C6 rat glioma, the NB1691 and SKNAS human neuroblastoma lines, and NIH3T3 cells. We found that although there was some variation in the magnitude of gene induction between the different cell lines and in response to different UPR inducers, three pro-angiogenic factors - VEGF, IL-8 and Angiogenin were consistently up-regulated by ER stress (Figure 2-2 to Figure 2-6). FGF2 is up-regulated only in Daoy cells, down-regulated in C6 and NIH3T3 cells, and not detectable in the two neuroblastoma tumor lines which suggest that this pro-angiogenic factor may not be a common UPR target. When the magnitude of induction of the various factors was compared to that obtained with hypoxia, we found that their induction during ER stress were equal or even higher than that under hypoxia. For instance, VEGF was induced to a higher level by ER stress than by hypoxia in C6 and NIH3T3 cells and was equally induced by ER stress and hypoxia in other cells. IL-8 was induced to a much higher level by thapsigargin than by other stress conditions in all human cells. Since no IL-8 gene exists in rodent cells, no signal was observed in $\mathrm{C} 6$ and NIH3T3 cells. We also tested the level of intracellular protein and secretion of VEGF in response to UPR activation and hypoxia in the $\mathrm{C} 6$ rat glioma line, which consistently showed the highest induction of VEGF mRNA in response to ER stress. We found that both steady state cellular protein levels (Western blot) and secretion (ELISA) of VEGF were highly induced by all three methods of UPR induction (Figure 2-7). The induction level of VEGF secreted was comparable to or even higher than that observed in the hypoxia treated cells. There was also a difference in the magnitude of induction of UPR target genes in response to different UPR inducers, which also varied between the different lines. This suggests that the threshold for UPR activation may vary in response to different agents in a cell type specific manner. Surprisingly, the magnitude of UPR activation in response to different stressors did not always correspond to the magnitude of induction of pro-angiogenic factors. For instance, no glucose condition was the best UPR inducer for C6 cells; while VEGF level under thapsigargin stress is higher than that under no glucose. However, Western Blot and ELISA assays showed that protein and secretion level of VEGF was induced to the highest level by no glucose stress. 
Table 2-1. Characterization of the UPR in Daoy medulloblastoma cell line by microarray.

\begin{tabular}{|c|c|c|c|}
\hline Gene & Fold $\uparrow 3 \mathrm{hr}$ & Fold $\uparrow 8 \mathrm{hr}$ & Pathway \\
\hline $\mathrm{BiP}$ & 5.4 & 10.1 & ATF6 \\
\hline GRP94 & 4.2 & 5.5 & ATF6 \\
\hline GRP170 & 3.0 & 6.1 & ATF6 \\
\hline XBP1 & 4.3 & 4.6 & ATF6 \\
\hline PDI & 1.4 & 7.5 & ATF6 \\
\hline HERP & 22.6 & 24.3 & ATF6/PERK \\
\hline $\mathrm{CHOP}$ & 36.8 & 34.3 & ATF6/PERK \\
\hline ERdj3 & 2.3 & 4.3 & Ire1 \\
\hline ERdj4 & 8.6 & 16.1 & Ire1 \\
\hline EDEM & 1.7 & 4.0 & Ire1 \\
\hline P58IPK & 5.0 & 6.9 & Ire1 \\
\hline ATF4 & 3.0 & 3.2 & PERK \\
\hline ATF3 & 7.0 & 4.5 & PERK \\
\hline GADD34 & 4.6 & 6.5 & PERK \\
\hline VEGF & 2.7 & 5.5 & $? ? ? ?$ \\
\hline FGF2 & 1.5 & 3.7 & ???? \\
\hline Angiogenin & 1.5 & 5.2 & ???? \\
\hline IL-8 & 30.0 & 15.6 & ???? \\
\hline
\end{tabular}


C6

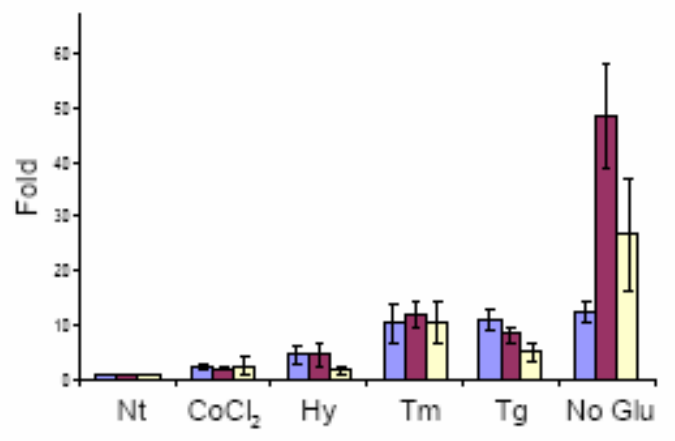

Daoy

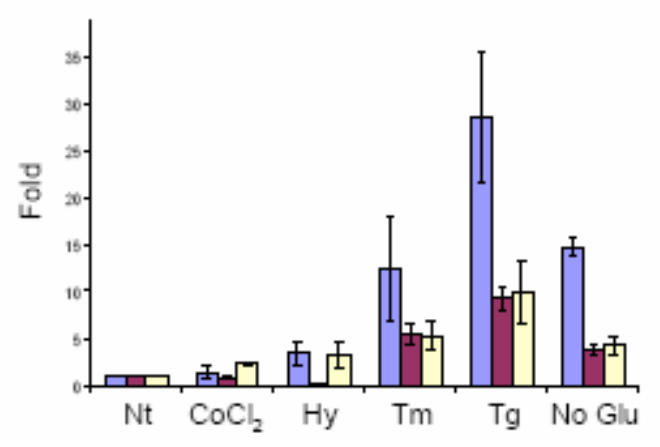

NIH3T3

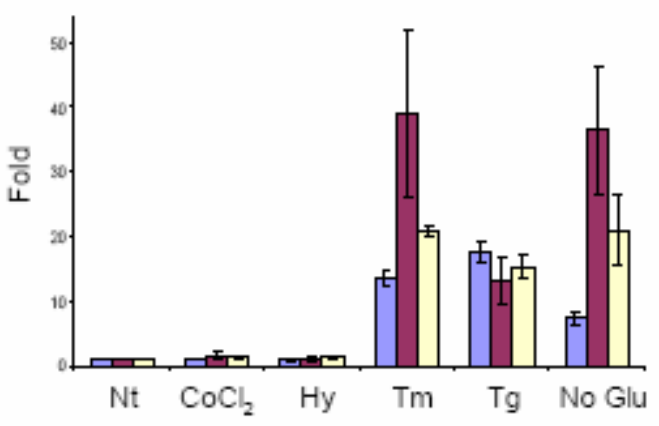

NB-1691

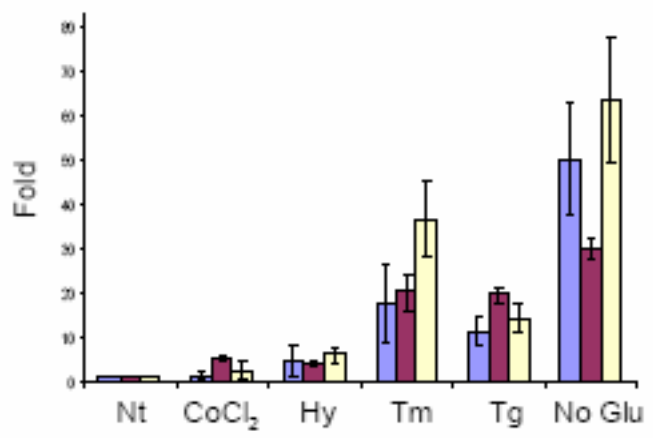

SK-N-AS

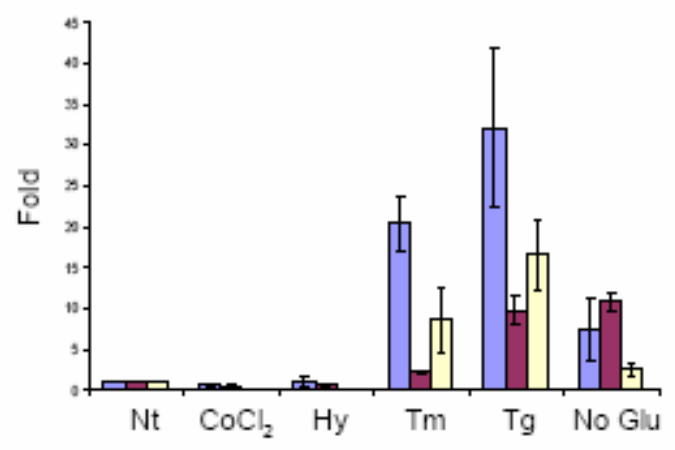

Figure 2-2. Induction of UPR targets in different cell lines. Cell lines of C6 rat glioma, NIH3T3 mouse fibroblast, Daoy human medulloblastoma, NB-1691 and SK-N-AS human neuroblastoma were treated with $100 \mathrm{uM} \mathrm{CoCl} 2,1 \% \mathrm{O} 2$ hypoxia (Hy), $2.5 \mathrm{ug} / \mathrm{mL}$ tunicamycin (Tm), 1uM thapsigargin ( Tg) or no glucose media (No Glu) for 24 hours. RNA was extracted for quantitative RT-PCR analysis on UPR targets BiP (blue), CHOP (red) and GRP170 (yellow). All experiments were performed in triplicate. Data represent the mean value $\pm \mathrm{SD}$. 
C6

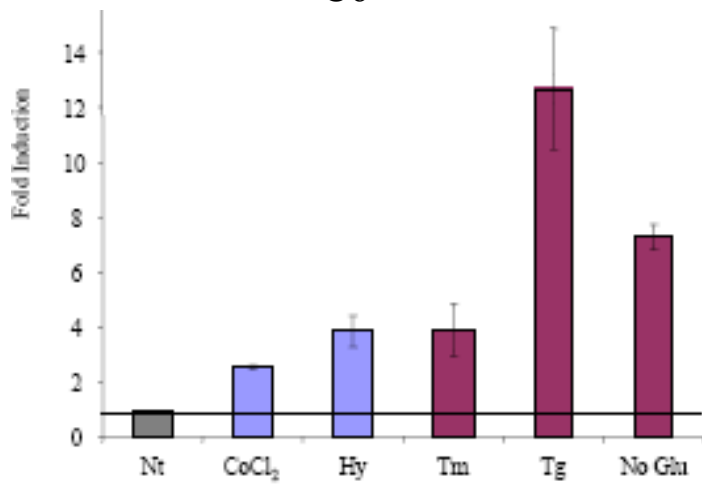

Daoy

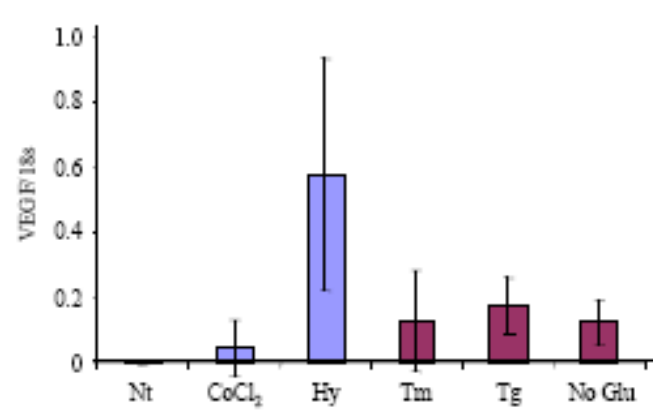

NIH3T3

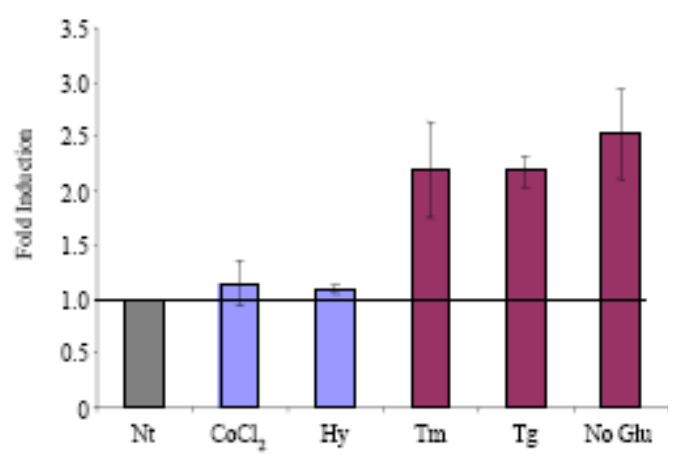

NB-1691

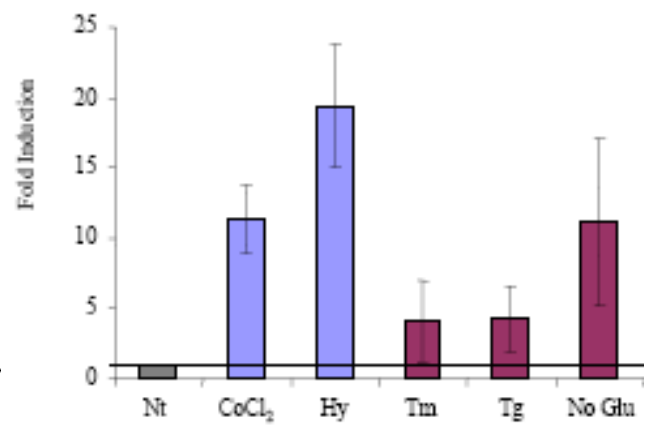

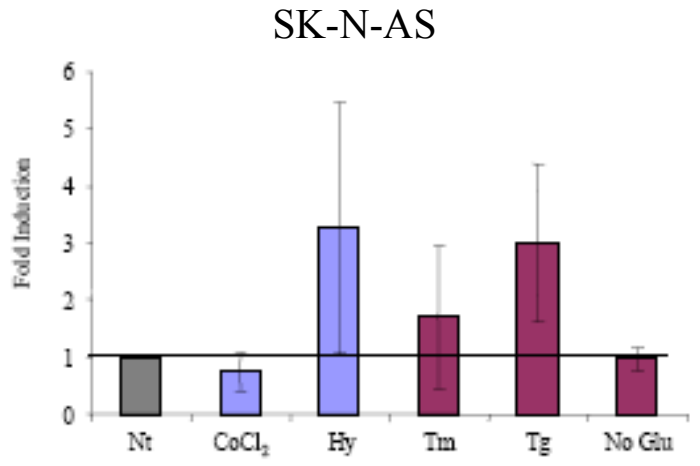

Figure 2-3. Induction of VEGF in different cell lines. Cell lines of C6 rat glioma, NIH3T3 mouse fibroblast, Daoy human medulloblastoma, NB-1691 and SK-N-AS human neuroblastoma were treated with $100 \mathrm{uM} \mathrm{CoCl} 2,1 \% \mathrm{O} 2$ hypoxia $(\mathrm{Hy}), 2.5 \mathrm{ug} / \mathrm{mL}$ tunicamycin (Tm), 1 uM thapsigargin (Tg) or no glucose media (No Glu) for 24 hours. RNA was extracted for quantitative RT-PCR analysis on VEGF. All experiments were performed in triplicate. Data represent the mean value \pm SD. 
C6

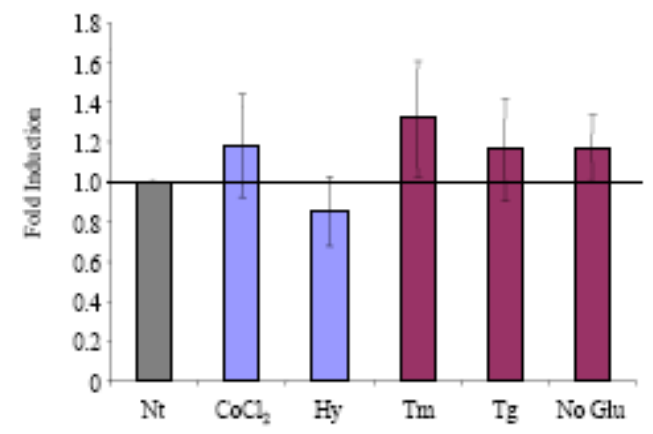

NB-1691

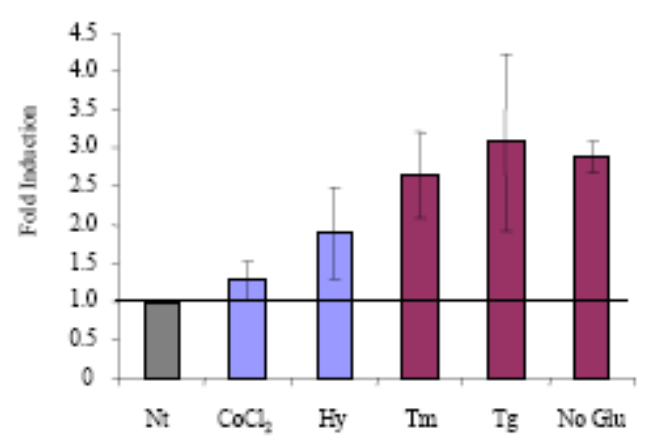

Daoy

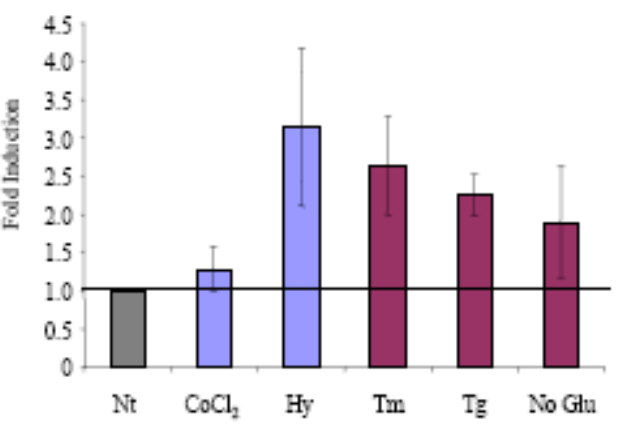

SK-N-AS

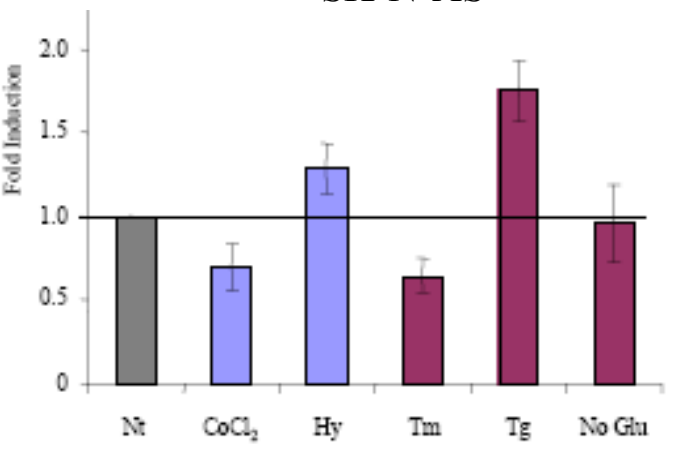

Figure 2-4. Induction of Angiogenin in different cell lines. Cell lines of C6 rat glioma, NIH3T3 mouse fibroblast, Daoy human medulloblastoma, NB-1691 and SK-N-AS human neuroblastoma were treated with $100 \mathrm{uM} \mathrm{CoCl} 2,1 \% \mathrm{O} 2$ hypoxia (Hy), $2.5 \mathrm{ug} / \mathrm{mL}$ tunicamycin (Tm), 1uM thapsigargin (Tg) or no glucose media (No Glu) for 24 hours. RNA was extracted for quantitative RT-PCR analysis on Angiogenin. No signal was observed in NIH3T3 cells. All experiments were performed in triplicate. Data represent the mean value $\pm \mathrm{SD}$. 

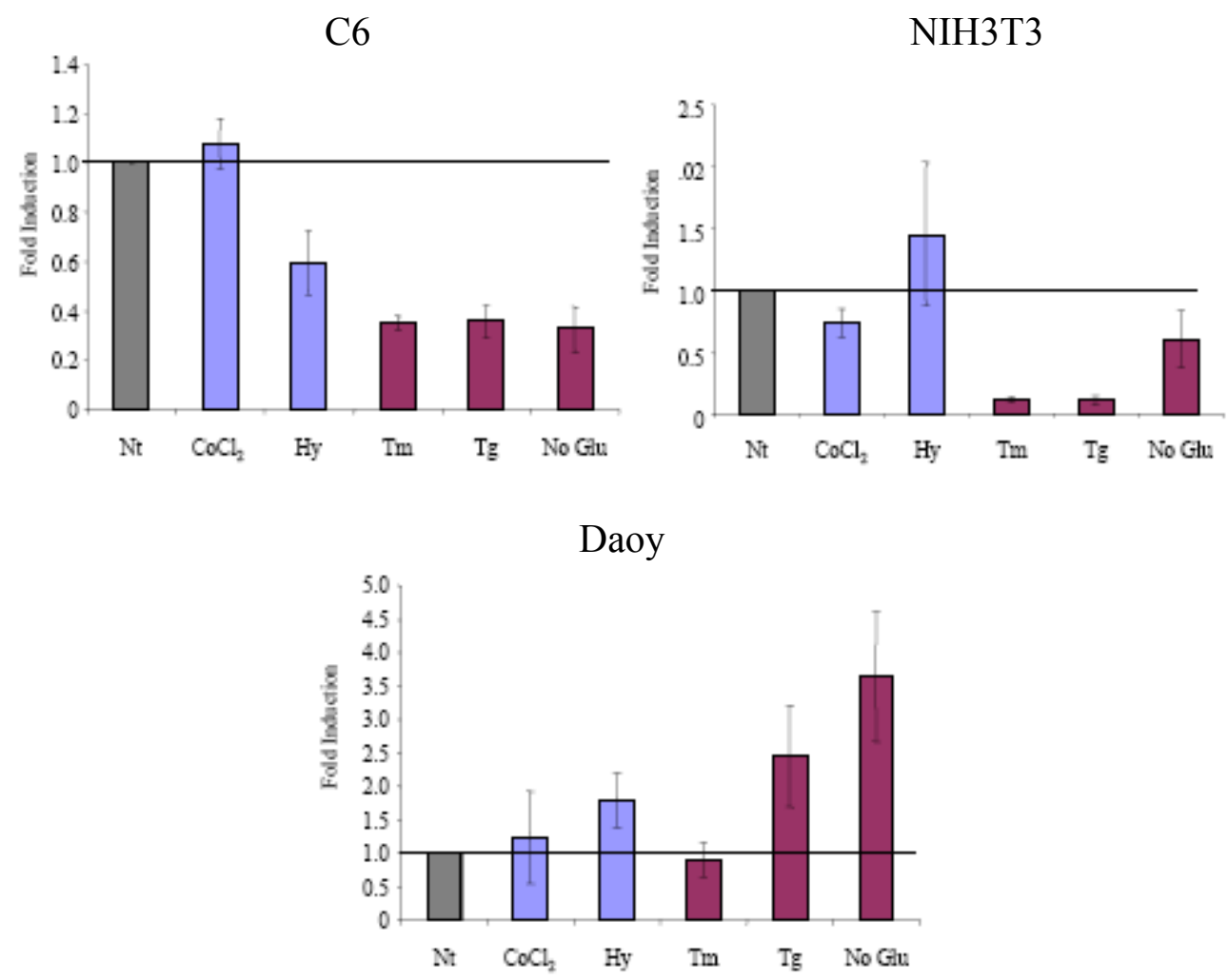

Figure 2-5. Induction of FGF2 in different cell lines. Cell lines of C6 rat glioma, NIH3T3 mouse fibroblast, Daoy human medulloblastoma, NB-1691 and SK-N-AS human neuroblastoma were treated with $100 \mathrm{uM} \mathrm{CoCl} 2,1 \% \mathrm{O} 2$ hypoxia $(\mathrm{Hy}), 2.5 \mathrm{ug} / \mathrm{mL}$ tunicamycin (Tm), 1uM thapsigargin ( $\mathrm{Tg}$ ) or no glucose media (No Glu) for 24 hours. RNA was extracted for quantitative RT-PCR analysis on FGF2. No signal was observed in SK-N-AS and NB-1691 cells. All experiments were performed in triplicate. Data represent the mean value $\pm \mathrm{SD}$. 
Daoy

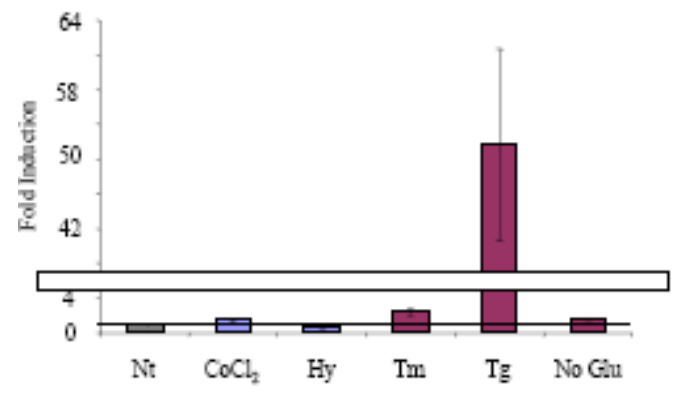

NB-1691

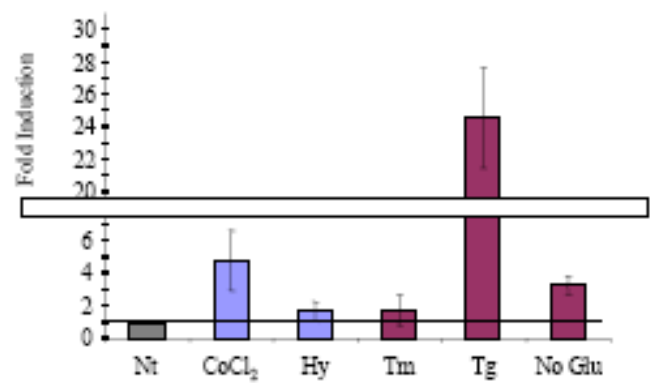

SK-N-AS

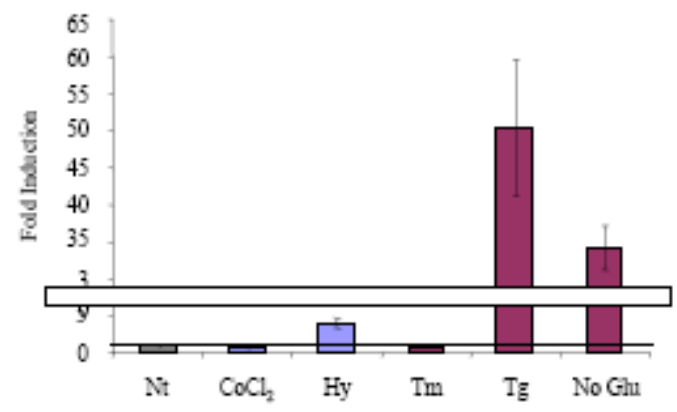

Figure 2-6. Induction of IL-8 in different cell lines. Cell lines of C6 rat glioma, NIH3T3 mouse fibroblast, Daoy human medulloblastoma, NB-1691 and SK-N-AS human neuroblastoma were treated with $100 \mathrm{uM} \mathrm{CoCl} 2,1 \% \mathrm{O} 2$ hypoxia $(\mathrm{Hy}), 2.5 \mathrm{ug} / \mathrm{mL}$ tunicamycin (Tm), 1uM thapsigargin (Tg) or no glucose media (No Glu) for 24 hours. RNA was extracted for quantitative RT-PCR analysis on IL-8. The gene of IL-8 does not exist in rats or mice. All experiments were performed in triplicate. Data represent the mean value $\pm \mathrm{SD}$. 
A.

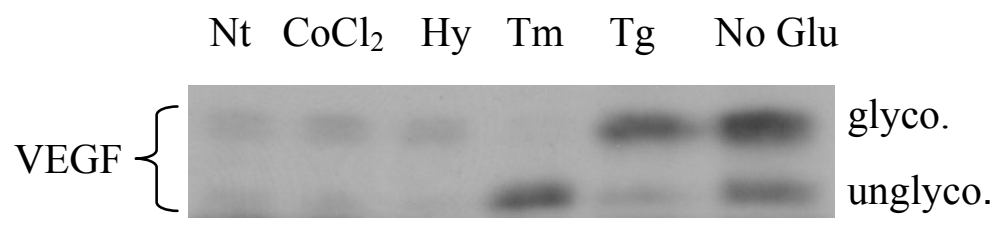

$\operatorname{Hsc} 70$

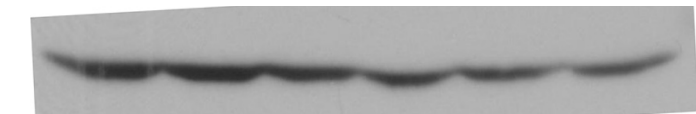

B.

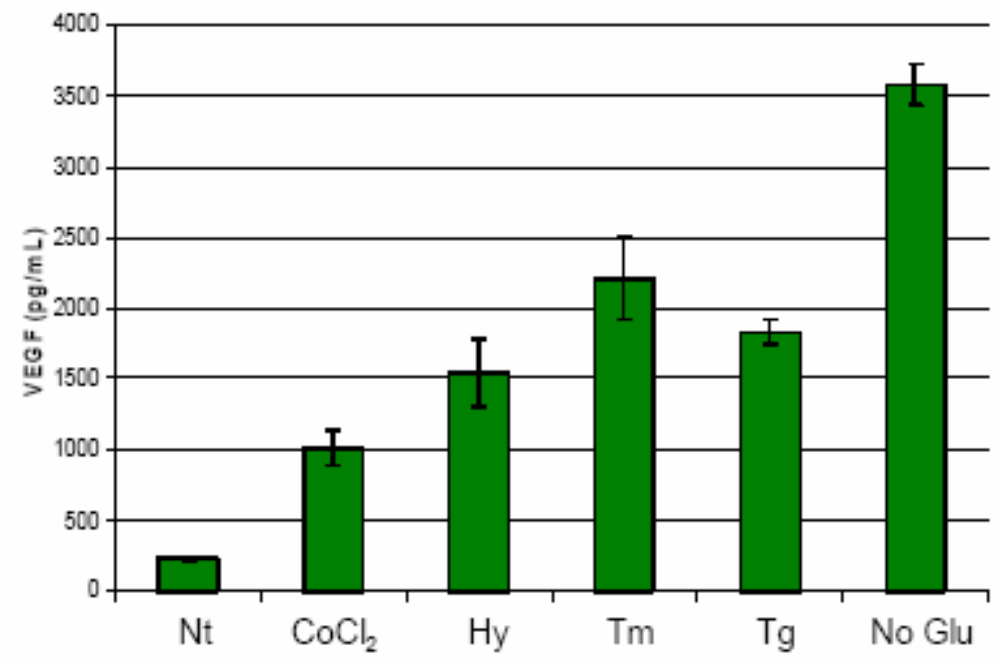

Figure 2-7. Induction of VEGF protein synthesis and secretion. C6 cells were treated with $100 \mathrm{uM} \mathrm{CoCl} 2,1 \% \mathrm{O} 2$ hypoxia (Hy), 2.5ug/mL tunicamycin ( Tm), 1uM thapsigargin (Tg) or no glucose media (No Glu) for 24 hours. (A) Cell lysates were run on $12 \%$ SDS gel. Western Blot was performed with an antibody specific for VEGF. Hsc70 signals serve as a control for protein loading. Western Blot was performed in duplicate. Both have similar results represented here. (B) After treatment, conditioned media were collected for ELISA analysis by commercial VEGF ELISA kit from R\&D systems. ELISA was performed in triplicate. Data represent the mean concentration $\pm \mathrm{SD}$. 


\section{Mechanism of Increase of VEGF mRNA by UPR Activation}

While the mRNA level of VEGF, IL-8 and Angiogenin were clearly increased during UPR activation in our study, another group also found that VEGF and IL-8 were induced in TSE human breast adenocarcinoma line by ER stress inducers such as tunicamysin, glucose depriviation, A23187 and Brefeldin A (Marjon et al., 2004). However, the mechanism of induction of pro-angiogenic factors is still not well understood. A previous study showed ATF4 transcriptionally up-regulated VEGF by using homocysteine treatment to induce ER stress (Roybal et al., 2004). On the other hand, several groups showed that the induction of these factors in response to hypoxia or glucose depriviation is in large part an increase in the stability of their mRNA (Levy et al., 1995; Levy et al., 1996; Yun et al., 2005). Thus, an understanding of the mechanism of UPR activation in regulating mRNA level of them is required. Here I performed several experiments to test how VEGF, one of the most important pro-angiogenic factors in tumor angiogenesis, is regulated during UPR activation in C6 rat glioma cells in vitro.

As a first step, I performed a time-course experiment to determine the kinetics of VEGF mRNA induction. C6 cells were incubated in complete media or treated with hypoxia, thapsigargin or no glucose for 3, 8, 16 or 24 hours. Total RNA was extracted from cells, and quantitative real-time PCR was performed to determine the VEGF mRNA levels in each sample. The data (Figure 2-8) showed that VEGF mRNA was induced as early as 3 hour in response to ER stress or hypoxia and continued to increase through the time course. I did not treat C6 cells with ER stress inducing agents or hypoxia for longer than 24 hours, because the cells started dying after that point. Thus, in later experiments, I treated the cells for no more than 12 hours, which gave me a strong induction of VEGF while still keeping the $\mathrm{C} 6$ cells healthy.

The next step was to determine whether the increase in VEGF mRNA by the UPR was due to transcriptional activation or to an increase in VEGF mRNA stability. To measure the half-live of VEGF mRNA, an mRNA turnover experiment was performed. C6 cells were untreated $(\mathrm{Nt})$ or pre-treated with $1 \% \mathrm{O}_{2}$ to induce hypoxic responses $(\mathrm{Hy})$, thapsigargin (Tg) or no glucose media (No Glu) for 6 hours. Next, $5 \mathrm{ug} / \mathrm{ml}$ actinomycin $\mathrm{D}$ was added to the cultured cells to inhibit transcription. The cells were then incubated for the indicated times, and total RNA was extracted. Quantitative real-time PCR was performed to determine that amount of VEGF mRNA that remained. The result of this experiment (Figure 2-9) showed that the half-life of VEGF in response to thapsigargin or no glucose treatment was much longer than that observed under control conditions, while its half-life in response to hypoxia was not significantly changed. This result demonstrates that the increase of VEGF mRNA observed in response to UPR activation is at least partially due to the stabilization of this message, while the higher VEGF message level under hypoxia may be only due to transactivation of VEGF by a transcription factor complex including Hifl $\alpha$ or Hif $2 \alpha$. At the 30 minute time point in each of the treatment groups, I found that the levels of residual VEGF mRNA was even increased under ER stress or hypoxia conditions while that under normal condition kept unchanged. Our explanation is that the unspliced hnRNA would be spliced into matured mRNA and transported into cytosol during this 30 minute period. It leads to the delayed 


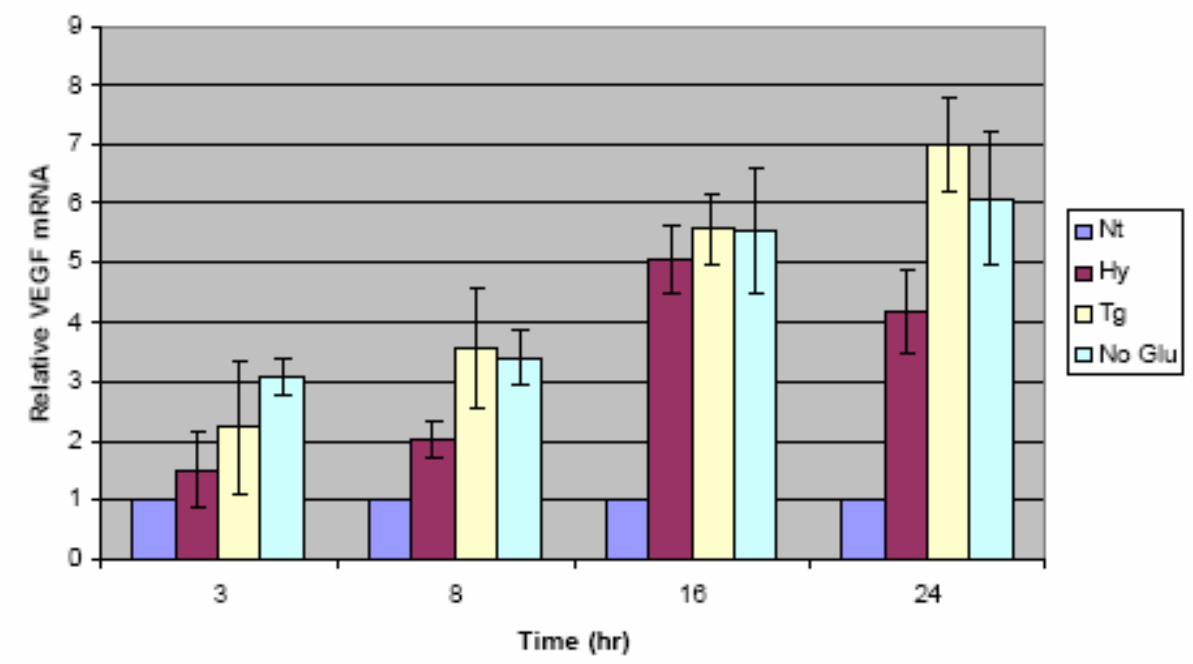

Figure 2-8. Induction of VEGF mRNA under stresses. C6 cells were treated with normal condition (Nt), $1 \% \mathrm{O}_{2}(\mathrm{Hy})$, thapsigargin ( $\mathrm{Tg}$ ) or no glucose media (No Glu) for indicated time periods. Total RNA was extracted for quantitative real-time PCR to test VEGF mRNA. The experiment was performed in duplicate. Data represent the mean value $\pm \mathrm{SD}$. 


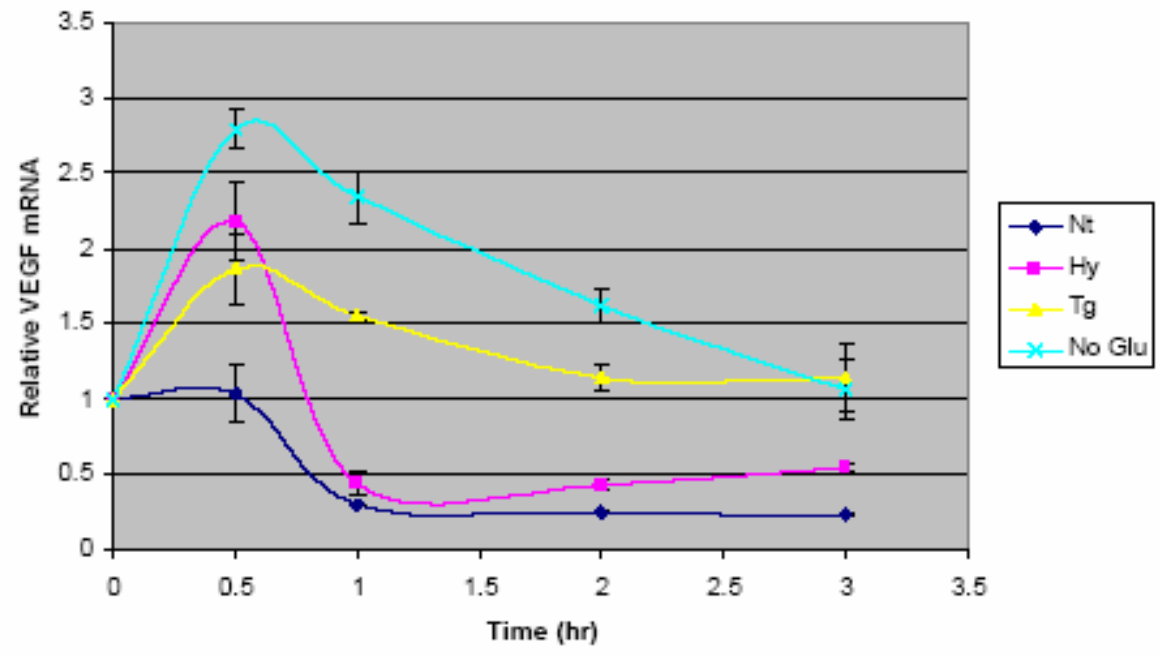

Figure 2-9. Decay of VEGF mRNA under stresses. C6 cells were pre-treated with normal condition $(\mathrm{Nt}), 1 \% \mathrm{O}_{2}(\mathrm{Hy})$, thapsigargin $(\mathrm{Tg})$ or no glucose media (No Glu) for 6 hours. Actinomycin D $(5 \mathrm{ug} / \mathrm{mL})$ was added to block transcription. After indicated time periods, total RNA was extracted from cells to perform quantitative real-time PCR to test VEGF mRNA. The experiment was performed in duplicate. Data represent the mean value $\pm \mathrm{SD}$. 
decrease of VEGF under regular condition. An increase of residual VEGF mRNA level under ER stress and hypoxia then represents that the amount of VEGF hnRNA under these conditions is much more than the amount of VEGF being degraded during the early 30 minutes period which implies that VEGF transcription rate may be increased in these stress conditions.

The transcription rate of a gene can be measured by examining the level of heterogeneous nuclear RNA (hnRNA), which exists only briefly before the introns are removed and the pre-RNA is fully processed into mature mRNA. This method was first described by Lipson and Baserga (Lipson and Baserga, 1989). To measure VEGF hnRNA, I designed the real-time PCR primers derived from exon2 and intron3 so that only hnRNA but not mRNA of VEGF would be amplified during the PCR reaction. However, a well purified mRNA without any DNA contamination is required, because genomic DNA can also be amplified by this primer pair and may cause a false signal problem. C6 cells were untreated or treated with $1 \%$ oxygen, thapsigargin or no glucose for 3, 8, 16 or 24 hours. Total RNA from each sample was extracted and treated with RNase-free DNase to remove the genomic DNA contaminate. Then quantitative real-time PCR was performed to determine the amount of VEGF hnRNA present. The result of this experiment (Figure 2-10) showed that the transcription rate of VEGF continuously increased during UPR activation or hypoxia treatment. This suggests that the increase of VEGF mRNA under UPR activation is also partially due to transactivation of the VEGF gene. As the experiment quantitiated VEGF hnRNA as a measure of the gene's transcription rate, I needed to demonstrate that these stress conditions did not negatively affect the rate of VEGF hnRNA splicing. To test this, I did an experiment which is very similar to mRNA decay assay. The only difference is that the decay of VEGF hnRNA instead of mature VEGF mRNA was examined. The data (Figure 2-11) demonstrates that the half life of VEGF hnRNA under different conditions is very similar. All undergo turnover in less than a 30-minute period. This further validated the conclusion that the VEGF gene is transactivated during UPR activation, and in C6 cells this rate was even higher than that observed in response to hypoxia. Taken together, my data demonstrates that the UPR contributes to increases in VEGF mRNA by two distinct methods: transcriptional transactivation and reduced turnover.

To further determine which UPR downstream transcription factor contributes to transactivation of the VEGF gene, we listed several UPR downstream transcription factors that can be candidates to promote VEGF transactivation. Among these factors, ATF6 is an ER transmembrane protein whose cytosolic domain is a transcription factor and is activated during ER stress by cleavage from ER membrane and translocating into nucleus (Ye et al., 2000). ATF4 is another ER stress induced transcription factor. Its activation is through shifting its translation starting sites mediated by eIF $2 \alpha$ phosphorylation (Harding et al., 2000). XBP1 is a transcription factor which is expressed in full lenth only under ER stress through reading-frame shift mediated by UPR activated IRE1 endonuclease activity (Calfon et al., 2002; Yoshida et al., 2001). NFкB is an important anti-apoptotic factor which is activated by the UPR through depleting its inhibitor I $\mathrm{B}$ (Jiang et al., 2003). Finally, Hif2 $\alpha$ which is regularly activated during hypoxia has been shown to be up-regulated by the UPR in our microarray assay. With the 


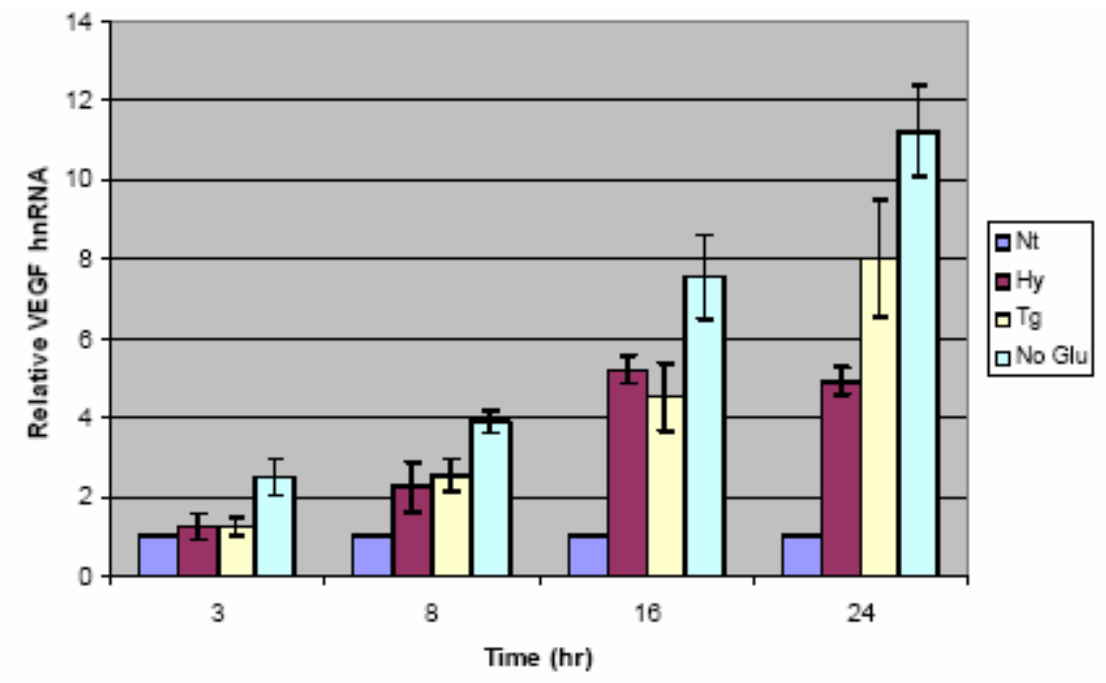

Figure 2-10. VEGF is transcriptionally up-regulated in response to the UPR. C6 cells were treated with normal condition $(\mathrm{Nt}), 1 \% \mathrm{O}_{2}(\mathrm{Hy})$, thapsigargin $(\mathrm{Tg})$ or no glucose media (No Glu) for indicated time periods. Total RNA was extracted for quantitative real-time PCR to test VEGF hnRNA. The experiment was performed in duplicate. Data represent the mean value $\pm \mathrm{SD}$. 


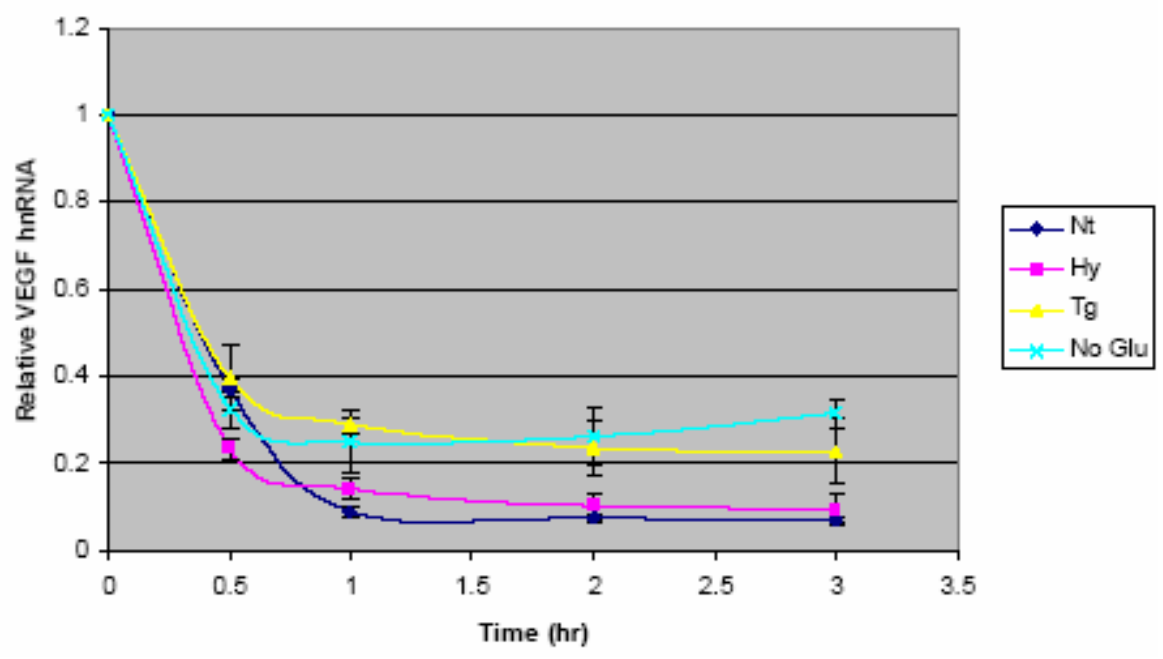

Figure 2-11. UPR activation does not significantly affect hnRNA splicing. C6 cells were pre-treated with normal condition $(\mathrm{Nt}), 1 \% \mathrm{O} 2(\mathrm{Hy})$, thapsigargin $(\mathrm{Tg})$ or no glucose media (No Glu) for 6 hours. Actinomycin D $(5 \mathrm{ug} / \mathrm{mL})$ was added to block transcription. After indicated time periods, total RNA was extracted from cells to perform quantitative real-time PCR to test VEGF hnRNA. The experiment was performed in duplicate. Data represent the mean value $\pm \mathrm{SD}$. 
list of UPR downstream transcription factors, I used rVista to analyze and look for potential binding sites for each factors. Interestingly, four of these five factors do have their potential binding sequences found in the $8 \mathrm{k}$ up-stream promoter region of VEGF gene of mouse, rat and human (Figure 2-12). Currently, we are trying to find evidence to show that any of these factors really bind to these sites under ER stress condition by using Chromotin IP method to test protein-chromosome interaction. Our recent data showed that XBP-1 may bind to VEGF promoter at $-1 \mathrm{k}$ and $-5 \mathrm{k}$ region in response to ER stress. We are currently validating these data and testing other binding sites of other transcription factors.

Several kinases have been shown to stabilize VEGF mRNA in response to different stresses such as hypoxia and glucose deprivation. In a recent study, scientists found that AMPK was activated during glucose deprivation which contributes to the increase of VEGF mRNA stability (Yun et al., 2005). Their research also suggests that JNK may be the upstream kinase of AMPK. Interestingly, JNK has been shown to be activated by IRE1 through TRAF2 during UPR activation (Urano et al., 2000). Another kinase p38 MAPK, which has been shown to be activated by PERK during ER stress (Liang et al., 2006), also increases mRNA stability of VEGF through an AMPK-p38 MAPK cascade in response to ischemic injury (Ouchi et al., 2005). In addition, p38 MAPK and PI3 kinase has been reported to activate ARE binding protein like HuR (Winzen et al., 1999) which can stabilize VEGF mRNA. To determine which kinase plays a role in increasing VEGF mRNA stability in C6 cells, I used specific kinase inhibitors to inhibit each of these kinases during ER stress and test whether it can inhibit VEGF mRNA up-regulation. The result showed that both p38 MAPK inhibitor SB203580 and AMPK inhibitor compound C can efficiently inhibit VEGF mRNA upregulation by the UPR without reducing VEGF transcription rate (Figure 2-13); JNK inhibitor SP600580 inhibits VEGF mRNA up-regulation in response to ER stress and hypoxia by reducing VEGF transcription (Figure 2-14); while ERK and PI3K inhibitors do not inhibit the increase of VEGF mRNA (Figure 2-15). This suggests that both p38 MAPK and AMPK play an important role in increasing VEGF mRNA stability while JNK may increase VEGF transcription rate in response to ER stress. Future studies will address the specific factors which contribute to up-regulation of VEGF mRNA in more detail.

\section{Summary}

With more evidence of UPR activation in solid tumor, it is now important to understand what role the UPR plays in tumor survival and growth. In this project, I first found that several pro-angiogenic factors including VEGF, FGF2, IL-8 and Angiogenin are induced by UPR activation in the Daoy human medulloblastoma cells in vitro through a micro-array analysis. To confirm this observation, I did quantitative real-time PCR to test the level of known UPR targets and of these four pro-angiogenic factors in multiple cell lines in response to various ER stress inducing agents. I also measured their induction by hypoxia, which is a well-characterized inducer of pro-angiogenic factors. All three UPR targets including BiP, CHOP and GRP170 were highly induced in all of 


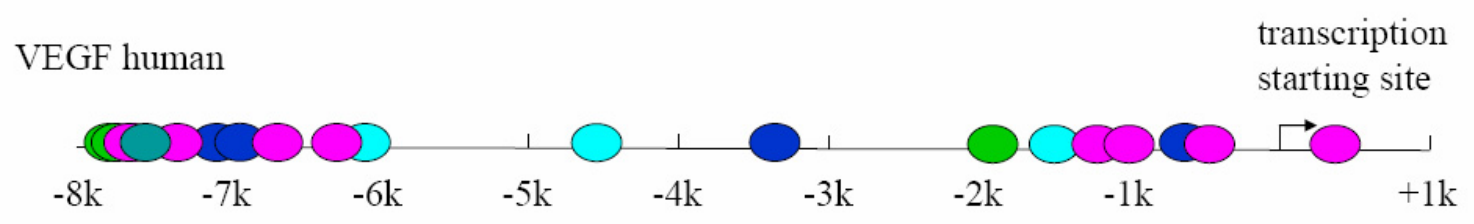

\section{VEGF mouse}

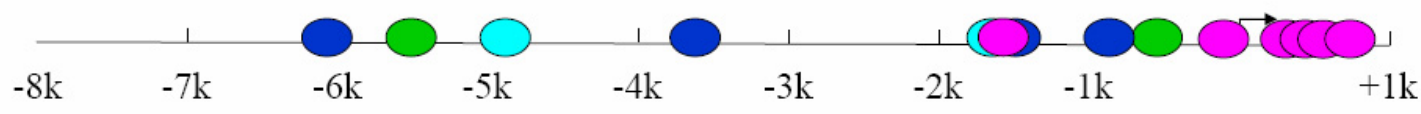

VEGF rat
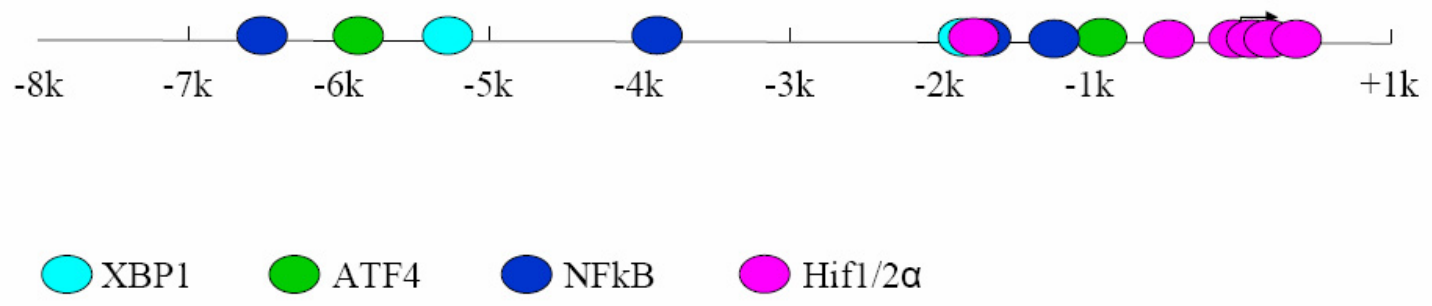

Figure 2-12. Potential binding sites of UPR downstream transcription factors in VEGF promoter. An online software, rVista was used to screen potential binding sequences of transcription factor XBP1 (light blue), ATF4 (green), NFאB (dark blue) and Hif2 $\alpha$ (pink) in $8 \mathrm{k}$ upstream promoter region of VEGF gene in human, mouse and rat. 
A.

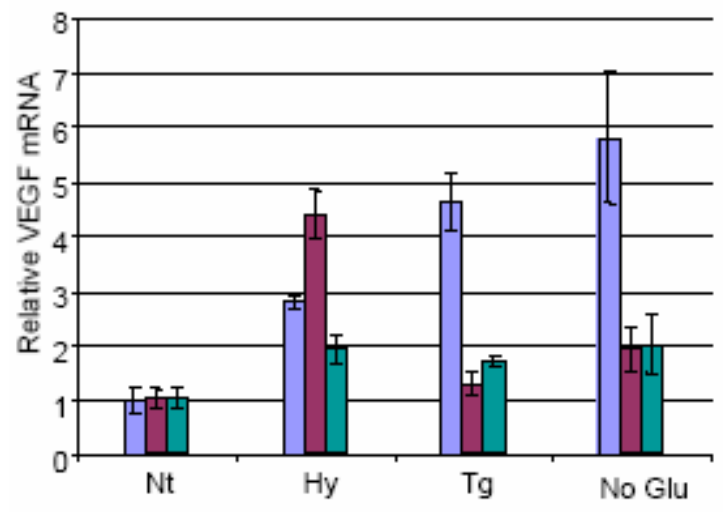

B.

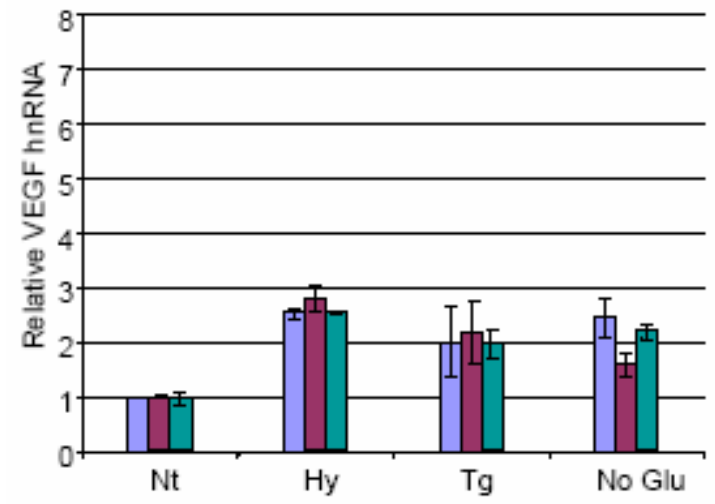

Figure 2-13. AMPK and p38 MAPK increase VEGF mRNA in response to UPR activation by increasing its stability. C6 cells were treated with normal condition (Nt), $1 \% \mathrm{O}_{2}(\mathrm{Hy})$, thapsigargin ( $\mathrm{Tg}$ ) or no glucose media (No Glu) for 8 hours with no inhibitor (blue) or with: compound C (red, AMPK inhibitor) or SB203580 (green, p38 MAPK inhibitor). Total RNA was extracted to test VEGF mRNA (A) and VEGF hnRNA (B) level of each sample. Experiments were performed in duplicate. 
A.

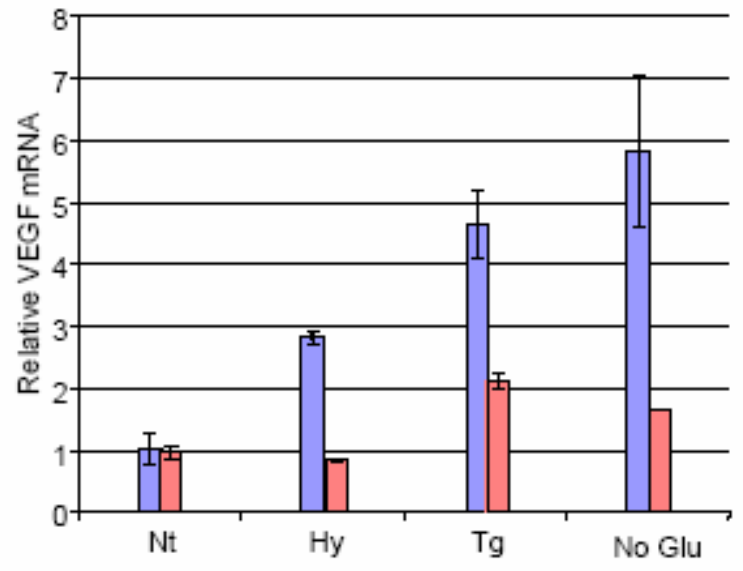

B.

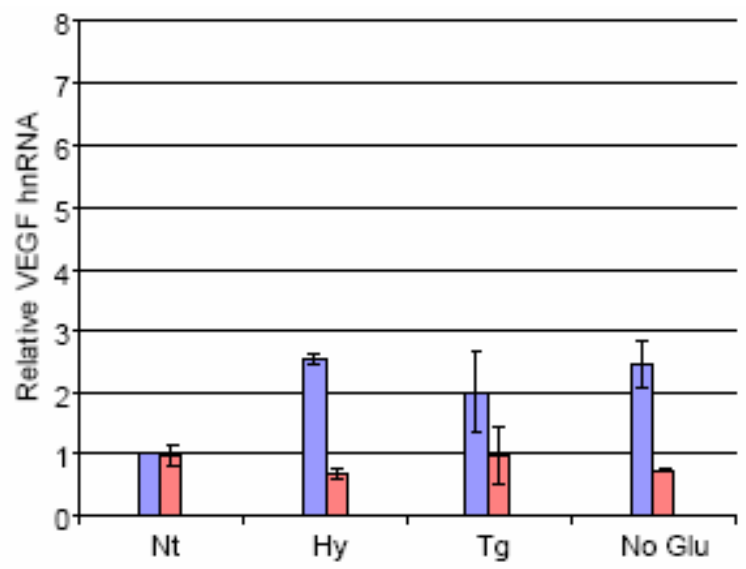

Figure 2-14. JNK increases VEGF mRNA in response to ER stress by increasing its transcription. C6 cells were treated with normal condition $(\mathrm{Nt}), 1 \% \mathrm{O}_{2}(\mathrm{Hy})$, thapsigargin (Tg) or no glucose media (No Glu) for 8 hours with no inhibitor (blue) or with: SP600125 (red, JNK inhibitor). Total RNA was extracted to test VEGF mRNA (A) and VEGF hnRNA (B) level of each sample. Experiments were performed in duplicate. 
A.

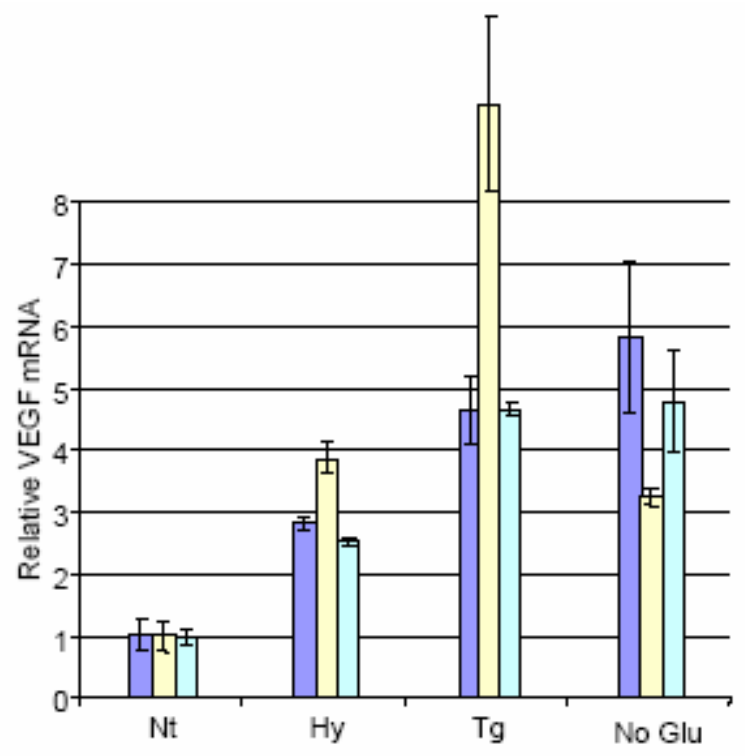

B.

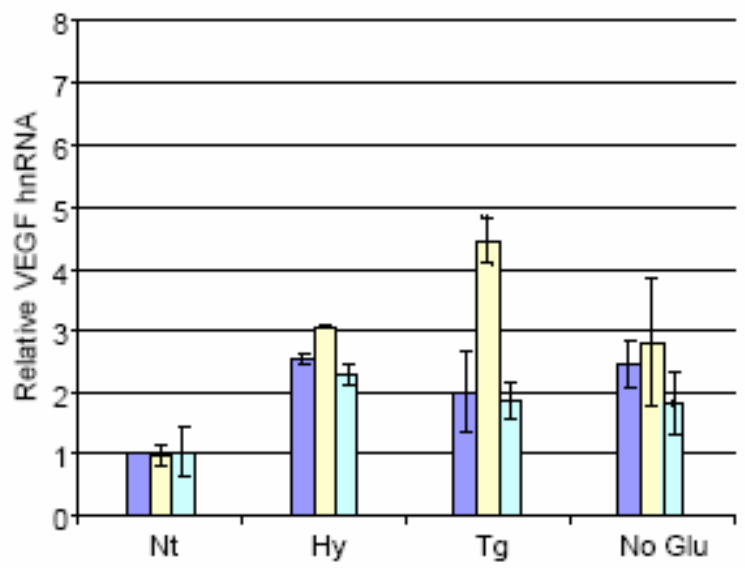

Figure 2-15. PI3K and ERK do not increase VEGF in response to UPR activation. C6 cells were treated with normal condition $(\mathrm{Nt}), 1 \% \mathrm{O}_{2}(\mathrm{Hy})$, thapsigargin $(\mathrm{Tg})$ or no glucose media (No Glu) for 8 hours with no inhibitor (blue) or with: LY294002 (yellow, PI3K inhibitor) or PD98059 (light green, ERK inhibitor). Total RNA was extracted to test VEGF mRNA (A) and VEGF hnRNA (B) level of each sample. Experiments were performed in duplicate. 
the cell lines by ER stress inducers tunicamysin, thapsigargin and no glucose media. Interestingly, I found that VEGF, IL-8 and Angiogenin were generally up-regulated during UPR activation in several cell lines including C6 rat glioma cells, NIH3T3 mouse fibroblast cells, Daoy human medulloblastoma cells, NB1691 and SKNAS human neuroblastoma cells while FGF2 was only up-regulated in Daoy cells. Furthermore, a western blot and an ELISA assay demonstrated that VEGF protein and secretion levels are also increased dramatically during UPR activation. Remarkably, this induction is even higher than that observed in response to hypoxia treatment, which is known to potently induce VEGF expression.

To understand the mechanism by which the UPR induces these pro-angiogenic factors, I chose VEGF expression in C6 cells as my target for further investigation. In order to test mRNA stability of VEGF under ER stress, an mRNA decay assay was performed. While the half-life of VEGF under control conditions is less than 30 minutes, I found that ER stress increased the half-life to $\sim 3$ hours. I also measured VEGF hnRNA levels under control and ER stress conditions as a method to quantify the rate of VEGF transcription. The data demonstrates that the level of VEGF hnRNA was dramatically induced in response to ER stress compared to control conditions. Putting these data together, I demonstrated that the induction of VEGF mRNA under ER stress is due to both transactivation of VEGF gene and an increase of VEGF mRNA stability. Thus, a number of UPR downstream transcription factors such as XBP-1, ATF4 and NFKB may play a role in transactivating the VEGF gene and a group of UPR downstream kinases may play a role in increasing VEGF mRNA stability through activating ARE binding protein complex.

We are currently investigating what transcription factors may contribute to transactivate the VEGF gene. Using rVista, we found binding sequences of several UPR downstream targets (such as XBP-1, ATF4 and NFkB) within 8k VEGF promoter of both human and rodent species. Our chromatin IP experiment suggests that XBP-1 may bind to its binding sites at both $-1 \mathrm{k}$ and $-5 \mathrm{k}$ region of VEGF promoter in the $\mathrm{C} 6$ cell line. In the mean time, to determine which kinases contribute to increase VEGF mRNA stability, I used specific inhibitors for each kinases including JNK, p38 MAPK, AMPK which have been shown to correlate to the increase of VEGF mRNA stability, and PI3K which has been shown to up-regulate VEGF transcription, and ERK which should have no effect to the level of VEGF mRNA. I found that both p38 MAPK inhibitor SB203580 and AMPK inhibitor compound $\mathrm{C}$ can efficiently inhibit VEGF mRNA up-regulation in response to the UPR without reducing VEGF transcription rate; while JNK inhibitor SP600125 can inhibit VEGF induction by inhibiting the increase of VEGF transcription. This suggests that both p38 MAPK and AMPK play an important role in increasing VEGF mRNA stability, and JNK may up-regulate VEGF transcription in response to ER stress. In Figure 2-16, we schematically showed how the UPR regulates VEGF mRNA in response to ER stress in vitro. Future studies will address the specific factors which contribute to up-regulation of VEGF mRNA in more detail. 


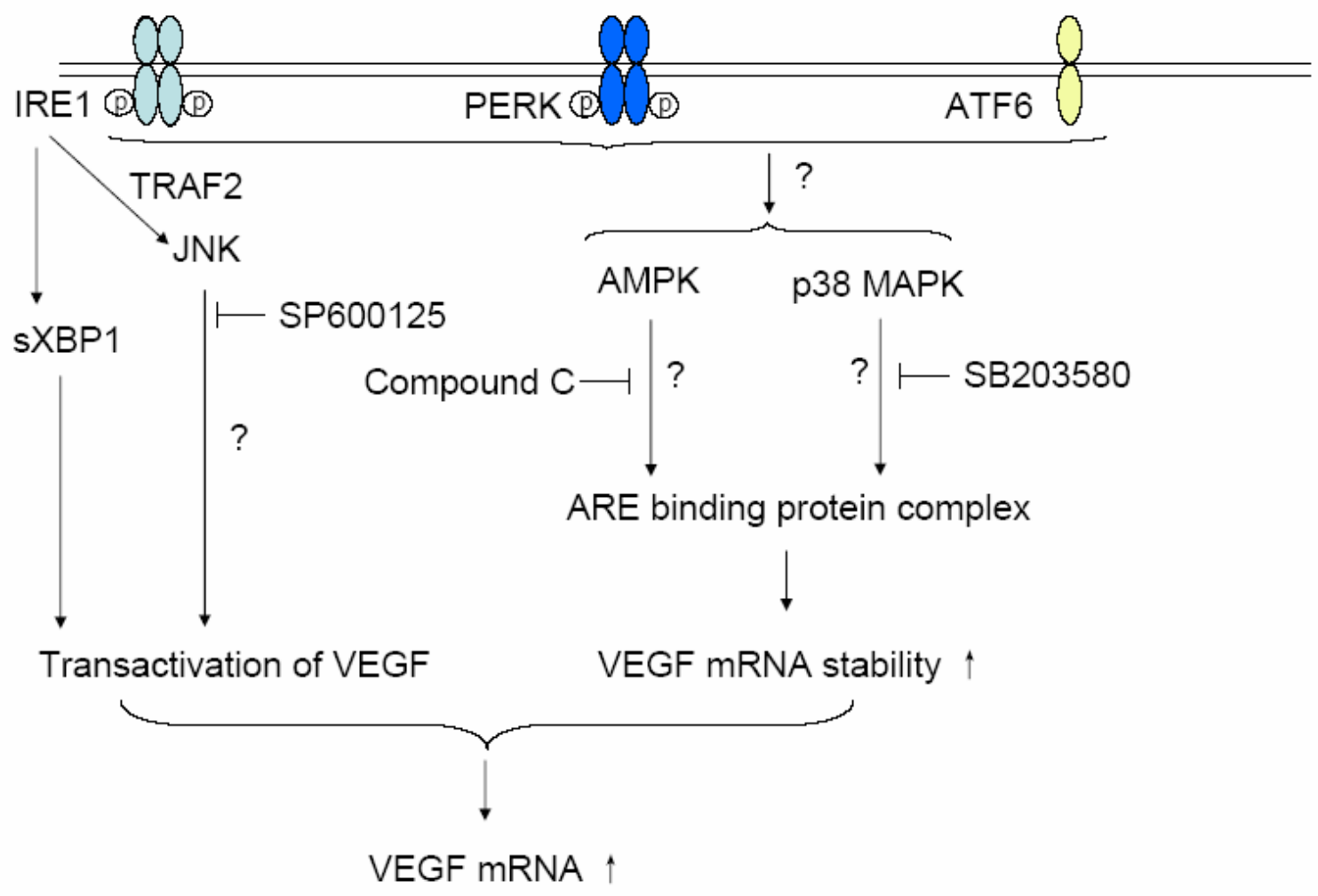

Figure 2-16. Model of UPR pathway regulating VEGF mRNA in C6 cells in vitro. 


\section{Chapter 3. General Discussion}

\section{Crosstalk of the UPR and the Hypoxia-induced Response}

While plenty of evidence demonstrates that genotoxic mutations are necessary to transform cancer cells, during rapid tumor growth, a series of cytotoxic conditions, such as altered $\mathrm{pH}$, low nutrients and hypoxia, can become rate limiting by poorly vascularized solid tumor cells. These conditions lead to activation of cytoprotective responses including the UPR (Feldman et al., 2005; Ma and Hendershot, 2004) and the hypoxiainduced response through activation of Hifl $\alpha$ or Hif2 $\alpha$ (Graeber et al., 1996; Hockel and Vaupel, 2001a; Hockel and Vaupel, 2001b). One of the most important pro-angiogenic factors VEGF has been shown to be induced under hypoxia condition through activation of Hifl $\alpha$ or Hif2 $\alpha$ (Poellinger and Johnson, 2004; Semenza, 2001). In our study and recent studies from other groups (Drogat et al., 2007; Marjon et al., 2004), VEGF was also showed to be activated by UPR activation. Our microarray data also suggest that Hif $2 \alpha$, a well known hypoxia induced transcription factor, was also induced during thapsigargin induced UPR activation in the Daoy cell line. On the other hand, the proapoptotic tumor suppressor p53 is stabilized during hypoxia through the reduction of MDM2 (Alarcon et al., 1999), but is destabilized during ER stress due to the

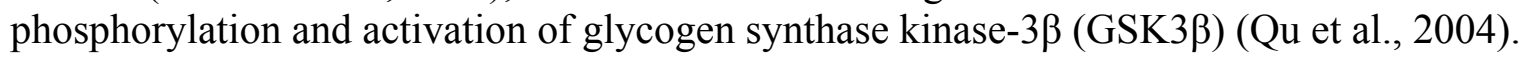
As both pathways can be activated in stressed tumor cells, it is important to know how the combination of activation of both pathways will regulate their downstream targets. In one of my experiments, I treated Daoy human medulloblastoma cells with both low glucose media and hypoxia together. Surprisingly, I found that rather than further activating the targets which are common to the UPR and the hypoxia induced response, up-regulation of targets downstream of both pathways, such Hif2 $\alpha$, was delayed and reduced (Figure 3-1). This suggests that these two pathways may negatively regulate the activation of each other rather than synergistically activate their targets. However, recent study from another group observed a higher induction of VEGF when cells were treated with both low glucose and hypoxia compared to that in single stress treatment in A549/8 human lung carcinoma cells (Drogat et al., 2007). Their data suggest that a target like VEGF was synergistically activated by both pathways. This contradictionary observation may be caused by different genotype or celltype of these two cell lines. Further experiments will characterize the crosstalk of the UPR and the hypoxia induced response in detail. It will help us to understand how this crosstalk affects tumor progress in vivo.

\section{UPR Activation and Growth of Solid Tumor}

While evidence of UPR activation has been shown in several studies, two groups have recently shown that the UPR is not only activated in solid tumors, but also contributes to its growth. In 2004, Dr. Albert Koong's group found that severe hypoxia $\left(<0.02 \% \mathrm{O}_{2}\right)$ can induce XBP1 at the transcriptional level and activate splicing of its 


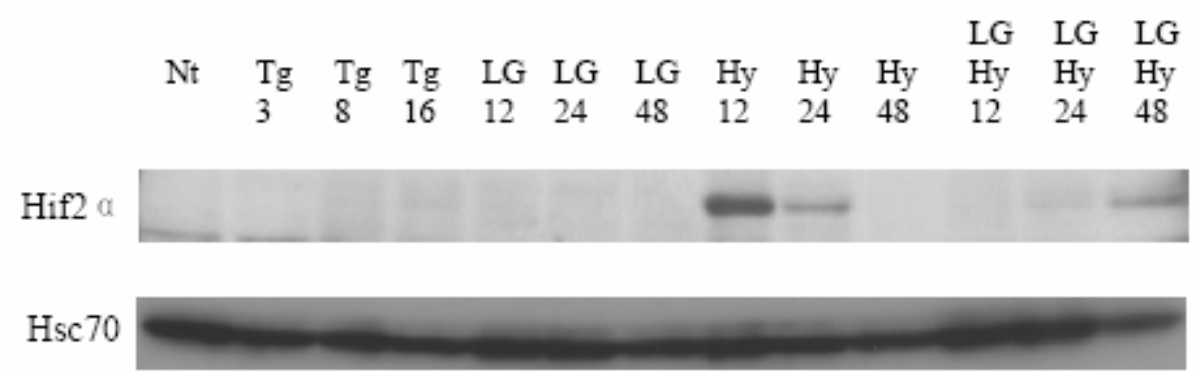

Figure 3-1. Induction of Hif2 $\alpha$ under different stresses. Daoy cells were treated with regular condition $(\mathrm{Nt})$, thapsigargin $(\mathrm{Tg}), 0.25 \mathrm{M}$ glucose media $(\mathrm{LG}), 1 \% \mathrm{O}_{2}(\mathrm{Hy})$ or $\mathrm{LG}+\mathrm{Hy}$ condition. Total cell lysate for each sample was run on SDS gels. Western Blot for Hif $2 \alpha$ was done with rabbit anti-Hif $2 \alpha$ antibody. Hsc70 serves as a control. 
mRNA, resulting in increased levels of spliced XBP1 protein (Romero-Ramirez et al., 2004), which is a typical evidence of ATF6 and IRE1 activation under the UPR (Calfon et al., 2002; Yoshida et al., 2001). After exposure to hypoxia, they found that apoptosis increased and clonogenic survival decreased in both XBP-1 knock-out and XBP-1 siRNA-transfected Ras and c-myc transformed MEFs compared to XBP-1 wild type MEFs. In this study, loss of XBP-1 severely inhibits tumor growth due to inhibition of the survival of transplanted tumor cells, which strongly suggests that UPR activated XBP-1 is essential for tumor survival and growth. Later in 2005, Dr. Constantinos Koumenis' group found that another UPR branch PERK was activated under extreme hypoxia $\left(<0.02 \mathrm{O}_{2}\right)$ and inactivation of PERK pathway by either dominant negative mutations in PERK or in the translation initiation factor eIF2a impairs cell survival under extreme hypoxia (Bi et al., 2005). They also found that tumors derived from PERK ${ }^{-/}$ MEFs are much smaller and exhibit higher levels of apoptosis in hypoxic areas compared to tumors with PERK pathway intact which suggests that PERK branch of the UPR is important for tumor survival and growth under hypoxia condition. These two studies clearly indicate that cells in hypoxia region of solid tumors may hijack the UPR pathway to survive the adverse environment.

In our early study, using microarray analysis we first found that several important pro-angiogenic factors such as VEGF, IL8 and Angiogenin were induced during UPR activation in Daoy medulloblastoma cell line. Their induction was further confirmed by real-time PCR and extended to other cell lines such as C6 rat glioma line, NIH3T3 mouse fibroblast line, SK-N-AS and NB1691 human neuroblastoma lines. Besides the mRNA level of these factors, protein and secretion level of VEGF was also dramatically induced by all tested UPR inducer in C6 cells. We will perform Western Blot and ELISA assays to test whether VEGF and the other two factors are also induced in each of these cell lines. Recently, two studies showed that tumor angiogenesis was induced either by PERK (Blais et al., 2006) or by IRE1 (Drogat et al., 2007). These data strongly implicate that UPR activation may play an important role in promoting tumor angiogenesis. In future studies, we will generate genetic mouse model to inhibit each branch of the UPR and test whether they are important to tumor angiogenesis in vivo.

\section{Evolution of the UPR Pathway}

The UPR pathway is present in all eukaryotic organisms and plays an important role in adapting cells to adverse environment that causes ER stress. In yeast, the whole UPR pathway is activated by the yeast Ire1 through the cleavage of HAC1 mRNA and the activation of its encoded transcription factor (Cox and Walter, 1996). This pathway is required for yeast to survive during ER stress but not during normal cell growth (Cox et al., 1993; Mori et al., 1993). The function of the UPR in yeast is to increase the degradative machinery to eliminate unfolded proteins, and to increase the volume and components of the entire secretory pathway to accommodate its burden and prevent aggregation of affected proteins (Ma and Hendershot, 2001). In C. elegans, this pathway is maintained but is supplemented with the PEK pathway, which, based on homology to mammalian PERK, would be expected to limit protein synthesis during ER stress (Ma 
and Hendershot, 2001). This suggests that, in addition to increase protein degradation and secretion, higher organisms like $\mathrm{C}$. elegans can also limit its protein synthesis to release ER stress.

In mammalian cells, the UPR pathway is expanded to four different branches. Instead of HAC1, IRE1 cleaves XBP-1 mRNA during ER stress in mammalian cells. This lead to the expression of full-length matured XBP-1 protein (Calfon et al., 2002; Yoshida et al., 2001) and the up-regulation of its downstream targets such as EDEM, ERdj3 and ERdj4 (Lee et al., 2003; Yoshida et al., 2003). PERK is also activated during ER stress. It phosphorylates eIF2 $\alpha$ and thus transiently inhibits protein synthesis and leads to cell cycle arrest due to loss of cyclin D1 (Brewer and Diehl, 2000; Harding et al., 1999; Shi et al., 1998). In addition to IRE1 and PERK, ATF6 is activated during ER stress and the transcription factor derived from its cytosolic domain transactivates ER chaperones BiP, GRP94 and another UPR downstream transcription factor XBP-1 (Yoshida et al., 1998; Yoshida et al., 2001). In addition to these cytoprotective responses, prolonged or acute ER stress can activate caspase 12 in mouse and caspase 4 in human and lead to apoptosis (Hitomi et al., 2004; Nakagawa et al., 2000). Thus, in mammalian, the UPR pathway can not only protect cells from ER stress by increasing ER capacity, increasing ER associated degradation (ERAD), limiting protein synthesis and cell cycle arrest, but also protect the organisms by eliminating severely stressed cells. Importantly, our data, as well as two recent published studies (Blais et al., 2006; Drogat et al., 2007), suggest that the UPR pathway may play an important role in promoting tumor angiogenesis. Our study also indicates that UPR activation may also play a role in physiological angiogenesis other than that in tumor progress because not only tumor cell lines, but also NIH3T3 mouse fibroblast cells have increased levels of pro-angiogenic factors in response to ER stress. If it is the case, our study will originally demonstrate that the UPR pathway is utilized by mammalian cells not only to defensively protect them from those adverse environments such as low oxygen, low nutrient and low $\mathrm{pH}$ when cells can not access blood vessels, but also to actively help these cells to resolve the severe conditions by inducing new blood supply around them.

\section{Implication of UPR Activation in Anti-angiogenic Cancer Therapy}

Tumor angiogenesis is regulated by a balance of pro- and antiangiogenic molecules, and when the balance shifts in favor of angiogenesis inducers, an angiogenic switch activates the normally quiescent vasculature to develop new blood vessels (Hanahan and Folkman, 1996). One of the most important pro-angiogenic factors VEGF has been shown to play an essential role in promoting tumor angiogenesis. A number of clinical trials are underway to test the utility of anti-VEGF or anti-VEGF receptor therapies in a variety of cancers. A recent phase III clinical trial demonstrated that bevacizumab (Avastin), a humanized monoclonal antibody against VEGF-A, in combination with conventional chemotherapy, increased overall survival by 5 months in colorectal cancer patients (Hurwitz et al., 2004), leading to FDA approval. However, as in other anti-cancer therapeutic strategies, apparent resistance to antiangiogenic therapies has been described in clinical trials and in xenotransplant tumor models (Kerbel et al., 
2001; Miller et al., 2003; Miller et al., 2005). In one xenograft study, inhibition of VEGFR2 markedly disrupted angiogenic switching, persistent angiogenesis and initial tumor growth by inhibiting VEGF signal pathway in the early stage of treatment. However, in late-stage tumors, phenotypic resistance to VEGFR2 blockade emerged, as tumors regrew during treatment after an initial period of growth suppression (Casanovas et al., 2005). They found that this resistance is due to a reactivation of tumor angiogenesis, independent of VEGF and associated with hypoxia-mediated induction of other proangiogenic factors sunch as FGF2 (Casanovas et al., 2005). As we described in the previous chapter, several important pro-angiogenic factors were induced by the UPR. Studies from other groups showed that the UPR is fully activated under extreme hypoxia (Bi et al., 2005; Romero-Ramirez et al., 2004). Taking together, it suggests that UPR activation may play a role in the induction of pro-angiogenic factors and the consequent reactivation of tumor angiogenesis. If this is the case, a strategy combining the antiangiogenic therapy with the inhibition of UPR activation may help diminish the resistance problem in the late stage of treatment. Thus, a new drug designed to inhibit the key regulator to pro-angiogenic factors under the UPR may be the next step to approach the cure of cancer. 


\section{LIST OF REFERENCES}

Alarcon,R., Koumenis,C., Geyer,R.K., Maki,C.G., and Giaccia,A.J. (1999). Hypoxia induces p53 accumulation through MDM2 down-regulation and inhibition of E6mediated degradation. Cancer Res. 59, 6046-6051.

Benjamin,L.E., Golijanin,D., Itin,A., Pode,D., and Keshet,E. (1999). Selective ablation of immature blood vessels in established human tumors follows vascular endothelial growth factor withdrawal. J. Clin. Invest 103, 159-165.

Bi,M., Naczki,C., Koritzinsky,M., Fels,D., Blais,J., Hu,N., Harding,H., Novoa,I., Varia,M., Raleigh,J., Scheuner,D., Kaufman,R.J., Bell,J., Ron,D., Wouters,B.G., and Koumenis,C. (2005). ER stress-regulated translation increases tolerance to extreme hypoxia and promotes tumor growth. EMBO J. 24, 3470-3481.

Blais,J.D., Addison,C.L., Edge,R., Falls,T., Zhao,H., Wary,K., Koumenis,C., Harding,H.P., Ron,D., Holcik,M., and Bell,J.C. (2006). Perk-dependent translational regulation promotes tumor cell adaptation and angiogenesis in response to hypoxic stress. Mol. Cell Biol. 26, 9517-9532.

Blais,J.D., Filipenko,V., Bi,M., Harding,H.P., Ron,D., Koumenis,C., Wouters,B.G., and Bell,J.C. (2004). Activating transcription factor 4 is translationally regulated by hypoxic stress. Mol. Cell Biol. 24, 7469-7482.

Bole,D.G., Hendershot,L.M., and Kearney,J.F. (1986). Posttranslational association of immunoglobulin heavy chain binding protein with nascent heavy chains in nonsecreting and secreting hybridomas. J. Cell Biol. 102, 1558-1566.

Brewer,J.W. and Diehl,J.A. (2000). PERK mediates cell-cycle exit during the mammalian unfolded protein response. Proc. Natl. Acad. Sci. U. S. A. 97, 12625-12630.

Brodsky,J.L., Werner,E.D., Dubas,M.E., Goeckeler,J.L., Kruse,K.B., and McCracken,A.A. (1999). The requirement for molecular chaperones during endoplasmic reticulum-associated protein degradation demonstrates that protein export and import are mechanistically distinct. J. Biol. Chem. 274, 3453-3460.

Brostrom,C.O., Prostko,C.R., Kaufman,R.J., and Brostrom,M.A. (1996). Inhibition of translational initiation by activators of the glucose-regulated stress protein and heat shock protein stress response systems. Role of the interferon-inducible double-stranded RNAactivated eukaryotic initiation factor 2alpha kinase. J. Biol. Chem. 271, 24995-25002.

Calfon,M., Zeng,H., Urano,F., Till,J.H., Hubbard,S.R., Harding,H.P., Clark,S.G., and Ron,D. (2002). IRE1 couples endoplasmic reticulum load to secretory capacity by processing the XBP-1 mRNA. Nature 415, 92-96. 
Carmeliet,P., Mackman,N., Moons,L., Luther,T., Gressens,P., Van,V., I, Demunck,H., Kasper,M., Breier,G., Evrard,P., Muller,M., Risau,W., Edgington,T., and Collen,D. (1996). Role of tissue factor in embryonic blood vessel development. Nature 383, 73-75.

Casanovas,O., Hicklin,D.J., Bergers,G., and Hanahan,D. (2005). Drug resistance by evasion of antiangiogenic targeting of VEGF signaling in late-stage pancreatic islet tumors. Cancer Cell 8, 299-309.

Chatterjee,S., Hirota,H., Belfi,C.A., Berger,S.J., and Berger,N.A. (1997).

Hypersensitivity to DNA cross-linking agents associated with up-regulation of glucoseregulated stress protein GRP78. Cancer Res. 57, 5112-5116.

Chen,X., Ding,Y., Liu,C.G., Mikhail,S., and Yang,C.S. (2002). Overexpression of glucose-regulated protein 94 (Grp94) in esophageal adenocarcinomas of a rat surgical model and humans. Carcinogenesis 23, 123-130.

Cheresh,D.A. (1987). Human endothelial cells synthesize and express an Arg-Gly-Aspdirected adhesion receptor involved in attachment to fibrinogen and von Willebrand factor. Proc. Natl. Acad. Sci. U. S. A. 84, 6471-6475.

Cox,J.S., Shamu,C.E., and Walter,P. (1993). Transcriptional induction of genes encoding endoplasmic reticulum resident proteins requires a transmembrane protein kinase. Cell 73, 1197-1206.

Cox,J.S. and Walter,P. (1996). A novel mechanism for regulating activity of a transcription factor that controls the unfolded protein response. Cell 87, 391-404.

Drogat,B., Auguste,P., Nguyen,D.T., Bouchecareilh,M., Pineau,R., Nalbantoglu,J., Kaufman,R.J., Chevet,E., Bikfalvi,A., and Moenner,M. (2007). IRE1 signaling is essential for ischemia-induced vascular endothelial growth factor-A expression and contributes to angiogenesis and tumor growth in vivo. Cancer Res. 67, 6700-6707.

Ellgaard,L. and Helenius,A. (2003). Quality control in the endoplasmic reticulum. Nat. Rev. Mol. Cell Biol. 4, 181-191.

Feldman,D.E., Chauhan,V., and Koong,A.C. (2005). The unfolded protein response: a novel component of the hypoxic stress response in tumors. Mol. Cancer Res. 3, 597-605.

Fernandez,P.M., Tabbara,S.O., Jacobs,L.K., Manning,F.C., Tsangaris,T.N., Schwartz,A.M., Kennedy,K.A., and Patierno,S.R. (2000). Overexpression of the glucoseregulated stress gene GRP78 in malignant but not benign human breast lesions. Breast Cancer Res. Treat. 59, 15-26.

Ferrara,N. and vis-Smyth,T. (1997). The biology of vascular endothelial growth factor. Endocr. Rev. 18, 4-25.

Folkman,J. (1995). Angiogenesis in cancer, vascular, rheumatoid and other disease. Nat. Med. 1, 27-31. 
Folkman,J. (1996). Fighting cancer by attacking its blood supply. Sci. Am. 275, 150-154.

Gosky,D. and Chatterjee,S. (2003). Down-regulation of topoisomerase II alpha is caused by up-regulation of GRP78. Biochem. Biophys. Res. Commun. 300, 327-332.

Graeber,T.G., Osmanian,C., Jacks,T., Housman,D.E., Koch,C.J., Lowe,S.W., and Giaccia,A.J. (1996). Hypoxia-mediated selection of cells with diminished apoptotic potential in solid tumours. Nature 379, 88-91.

Hampton,R.Y. (2000). ER stress response: getting the UPR hand on misfolded proteins. Curr. Biol. 10, R518-R521.

Hanahan,D. and Folkman,J. (1996). Patterns and emerging mechanisms of the angiogenic switch during tumorigenesis. Cell 86, 353-364.

Harding,H.P., Novoa,I., Zhang,Y., Zeng,H., Wek,R., Schapira,M., and Ron,D. (2000). Regulated translation initiation controls stress-induced gene expression in mammalian cells. Mol. Cell 6, 1099-1108.

Harding,H.P., Zhang,Y., and Ron,D. (1999). Protein translation and folding are coupled by an endoplasmic-reticulum-resident kinase. Nature 397, 271-274.

Harding,H.P., Zhang,Y., Zeng,H., Novoa,I., Lu,P.D., Calfon,M., Sadri,N., Yun,C., Popko,B., Paules,R., Stojdl,D.F., Bell,J.C., Hettmann,T., Leiden,J.M., and Ron,D. (2003). An integrated stress response regulates amino acid metabolism and resistance to oxidative stress. Mol. Cell 11, 619-633.

Haze,K., Yoshida,H., Yanagi,H., Yura,T., and Mori,K. (1999). Mammalian transcription factor ATF6 is synthesized as a transmembrane protein and activated by proteolysis in response to endoplasmic reticulum stress. Mol. Biol. Cell 10, 3787-3799.

Helenius,A. (1994). How N-linked oligosaccharides affect glycoprotein folding in the endoplasmic reticulum. Mol. Biol. Cell 5, 253-265.

Hendershot,L.M., Ting,J., and Lee,A.S. (1988). Identity of the immunoglobulin heavychain-binding protein with the 78,000-dalton glucose-regulated protein and the role of posttranslational modifications in its binding function. Mol. Cell Biol. 8, 4250-4256.

Hitomi,J., Katayama,T., Eguchi,Y., Kudo,T., Taniguchi,M., Koyama,Y., Manabe,T., Yamagishi,S., Bando,Y., Imaizumi,K., Tsujimoto,Y., and Tohyama,M. (2004).

Involvement of caspase-4 in endoplasmic reticulum stress-induced apoptosis and Abetainduced cell death. J. Cell Biol. 165, 347-356.

Hockel,M. and Vaupel,P. (2001a). Biological consequences of tumor hypoxia. Semin. Oncol. 28, 36-41.

Hockel,M. and Vaupel,P. (2001b). Tumor hypoxia: definitions and current clinical, biologic, and molecular aspects. J. Natl. Cancer Inst. 93, 266-276. 
Holmgren,L., O'Reilly,M.S., and Folkman,J. (1995). Dormancy of micrometastases: balanced proliferation and apoptosis in the presence of angiogenesis suppression. Nat. Med. 1, 149-153.

Hughes,C.S., Shen,J.W., and Subjeck,J.R. (1989). Resistance to etoposide induced by three glucose-regulated stresses in Chinese hamster ovary cells. Cancer Res. 49, 44524454.

Hurwitz,H., Fehrenbacher,L., Novotny,W., Cartwright,T., Hainsworth,J., Heim,W., Berlin,J., Baron,A., Griffing,S., Holmgren,E., Ferrara,N., Fyfe,G., Rogers,B., Ross,R., and Kabbinavar,F. (2004). Bevacizumab plus irinotecan, fluorouracil, and leucovorin for metastatic colorectal cancer. N. Engl. J. Med. 350, 2335-2342.

Ikeda,J., Kaneda,S., Kuwabara,K., Ogawa,S., Kobayashi,T., Matsumoto,M., Yura,T., and Yanagi,H. (1997). Cloning and expression of cDNA encoding the human $150 \mathrm{kDa}$ oxygen-regulated protein, ORP150. Biochem. Biophys. Res. Commun. 230, 94-99.

Jamora,C., Dennert,G., and Lee,A.S. (1996). Inhibition of tumor progression by suppression of stress protein GRP78/BiP induction in fibrosarcoma B/C10ME. Proc. Natl. Acad. Sci. U. S. A. 93, 7690-7694.

Jiang,H.Y., Wek,S.A., McGrath,B.C., Scheuner,D., Kaufman,R.J., Cavener,D.R., and Wek,R.C. (2003). Phosphorylation of the alpha subunit of eukaryotic initiation factor 2 is required for activation of NF-kappaB in response to diverse cellular stresses. Mol. Cell Biol. 23, 5651-5663.

Kerbel,R.S., Yu,J., Tran,J., Man,S., Viloria-Petit,A., Klement,G., Coomber,B.L., and Rak,J. (2001). Possible mechanisms of acquired resistance to anti-angiogenic drugs: implications for the use of combination therapy approaches. Cancer Metastasis Rev. 20, 79-86.

Klagsbrun,M. and D'Amore,P.A. (1991). Regulators of angiogenesis. Annu. Rev. Physiol $53,217-239$.

Klagsbrun,M. and Moses,M.A. (1999). Molecular angiogenesis. Chem. Biol. 6, R217R224.

Koong,A.C., Chen,E.Y., and Giaccia,A.J. (1994). Hypoxia causes the activation of nuclear factor kappa B through the phosphorylation of I kappa B alpha on tyrosine residues. Cancer Res. 54, 1425-1430.

Kornfeld,R. and Kornfeld,S. (1985). Assembly of asparagine-linked oligosaccharides. Annu. Rev. Biochem. 54, 631-664.

Kostova,Z. and Wolf,D.H. (2003). For whom the bell tolls: protein quality control of the endoplasmic reticulum and the ubiquitin-proteasome connection. EMBO J. 22, 23092317. 
Koumenis,C., Naczki,C., Koritzinsky,M., Rastani,S., Diehl,A., Sonenberg,N., Koromilas,A., and Wouters,B.G. (2002). Regulation of protein synthesis by hypoxia via activation of the endoplasmic reticulum kinase PERK and phosphorylation of the translation initiation factor eIF2alpha. Mol. Cell Biol. 22, 7405-7416.

Kozutsumi,Y., Segal,M., Normington,K., Gething,M.J., and Sambrook,J. (1988). The presence of malfolded proteins in the endoplasmic reticulum signals the induction of glucose-regulated proteins. Nature 332, 462-464.

Ledoux,S., Yang,R., Friedlander,G., and Laouari,D. (2003). Glucose depletion enhances P-glycoprotein expression in hepatoma cells: role of endoplasmic reticulum stress response. Cancer Res. 63, 7284-7290.

Lee,A.H., Iwakoshi,N.N., and Glimcher,L.H. (2003). XBP-1 regulates a subset of endoplasmic reticulum resident chaperone genes in the unfolded protein response. Mol. Cell Biol. 23, 7448-7459.

Lee,A.S. (1992). Mammalian stress response: induction of the glucose-regulated protein family. Curr. Opin. Cell Biol. 4, 267-273.

Lee,A.S., Wells,S., Kim,K.S., and Scheffler,I.E. (1986). Enhanced synthesis of the glucose/calcium-regulated proteins in a hamster cell mutant deficient in transfer of oligosaccharide core to polypeptides. J. Cell Physiol 129, 277-282.

Levy,A.P., Levy,N.S., and Goldberg,M.A. (1996). Post-transcriptional regulation of vascular endothelial growth factor by hypoxia. J. Biol. Chem. 271, 2746-2753.

Levy,A.P., Levy,N.S., Loscalzo,J., Calderone,A., Takahashi,N., Yeo,K.T., Koren,G., Colucci,W.S., and Goldberg,M.A. (1995). Regulation of vascular endothelial growth factor in cardiac myocytes. Circ. Res. 76, 758-766.

Liang,S.H., Zhang,W., McGrath,B.C., Zhang,P., and Cavener,D.R. (2006). PERK (eIF2alpha kinase) is required to activate the stress-activated MAPKs and induce the expression of immediate-early genes upon disruption of ER calcium homoeostasis. Biochem. J. 393, 201-209.

Liao,N. and Hendershot,L.M. (2007). The unfolded protein response: contributions to development and disease. Cell Stress Proteins 4, 57-88.

Lin,H.Y., Masso-Welch,P., Di,Y.P., Cai,J.W., Shen,J.W., and Subjeck,J.R. (1993). The $170-\mathrm{kDa}$ glucose-regulated stress protein is an endoplasmic reticulum protein that binds immunoglobulin. Mol. Biol. Cell 4, 1109-1119.

Lipson,K.E. and Baserga,R. (1989). Transcriptional activity of the human thymidine kinase gene determined by a method using the polymerase chain reaction and an intronspecific probe. Proc. Natl. Acad. Sci. U. S. A. 86, 9774-9777. 
Ma,Y. and Hendershot,L.M. (2001). The unfolding tale of the unfolded protein response. Cell 107, 827-830.

Ma,Y. and Hendershot,L.M. (2003). Delineation of a negative feedback regulatory loop that controls protein translation during endoplasmic reticulum stress. J. Biol. Chem. 278, 34864-34873.

Ma,Y. and Hendershot,L.M. (2004). The role of the unfolded protein response in tumour development: friend or foe? Nat. Rev. Cancer 4, 966-977.

Mandic,A., Hansson,J., Linder,S., and Shoshan,M.C. (2003). Cisplatin induces endoplasmic reticulum stress and nucleus-independent apoptotic signaling. J. Biol. Chem. 278, 9100-9106.

Marjon,P.L., Bobrovnikova-Marjon,E.V., and Abcouwer,S.F. (2004). Expression of the pro-angiogenic factors vascular endothelial growth factor and interleukin-8/CXCL8 by human breast carcinomas is responsive to nutrient deprivation and endoplasmic reticulum stress. Mol. Cancer 3, 4 .

McCullough,K.D., Martindale,J.L., Klotz,L.O., Aw,T.Y., and Holbrook,N.J. (2001). Gadd153 sensitizes cells to endoplasmic reticulum stress by down-regulating Bcl 2 and perturbing the cellular redox state. Mol. Cell Biol. 21, 1249-1259.

Miller,K.D., Sweeney,C.J., and Sledge,G.W., Jr. (2003). The Snark is a Boojum: the continuing problem of drug resistance in the antiangiogenic era. Ann. Oncol. 14, 20-28.

Miller,K.D., Sweeney,C.J., and Sledge,G.W., Jr. (2005). Can tumor angiogenesis be inhibited without resistance? EXS 95-112.

Mori,K., Ma,W., Gething,M.J., and Sambrook,J. (1993). A transmembrane protein with a cdc2+/CDC28-related kinase activity is required for signaling from the ER to the nucleus. Cell 74, 743-756.

Mori,K., Sant,A., Kohno,K., Normington,K., Gething,M.J., and Sambrook,J.F. (1992). A $22 \mathrm{bp}$ cis-acting element is necessary and sufficient for the induction of the yeast KAR2 (BiP) gene by unfolded proteins. EMBO J. 11, 2583-2593.

Nakagawa,T. and Yuan,J. (2000). Cross-talk between two cysteine protease families. Activation of caspase-12 by calpain in apoptosis. J. Cell Biol. 150, 887-894.

Nakagawa,T., Zhu,H., Morishima,N., Li,E., Xu,J., Yankner,B.A., and Yuan,J. (2000). Caspase-12 mediates endoplasmic-reticulum-specific apoptosis and cytotoxicity by amyloid-beta. Nature 403, 98-103.

Novoa,I., Zeng,H., Harding,H.P., and Ron,D. (2001). Feedback inhibition of the unfolded protein response by GADD34-mediated dephosphorylation of eIF2alpha. J. Cell Biol. $153,1011-1022$. 
Ouchi,N., Shibata,R., and Walsh,K. (2005). AMP-activated protein kinase signaling stimulates VEGF expression and angiogenesis in skeletal muscle. Circ. Res. 96, 838-846.

Ozawa,K., Kuwabara,K., Tamatani,M., Takatsuji,K., Tsukamoto,Y., Kaneda,S., Yanagi,H., Stern,D.M., Eguchi,Y., Tsujimoto,Y., Ogawa,S., and Tohyama,M. (1999). 150-kDa oxygen-regulated protein (ORP150) suppresses hypoxia-induced apoptotic cell death. J. Biol. Chem. 274, 6397-6404.

Ozawa,K., Tsukamoto,Y., Hori,O., Kitao,Y., Yanagi,H., Stern,D.M., and Ogawa,S. (2001). Regulation of tumor angiogenesis by oxygen-regulated protein 150, an inducible endoplasmic reticulum chaperone. Cancer Res. 61, 4206-4213.

Papetti,M. and Herman,I.M. (2002). Mechanisms of normal and tumor-derived angiogenesis. Am. J. Physiol Cell Physiol 282, C947-C970.

Poellinger,L. and Johnson,R.S. (2004). HIF-1 and hypoxic response: the plot thickens. Curr. Opin. Genet. Dev. 14, 81-85.

Pouyssegur,J., Shiu,R.P., and Pastan,I. (1977). Induction of two transformation-sensitive membrane polypeptides in normal fibroblasts by a block in glycoprotein synthesis or glucose deprivation. Cell 11, 941-947.

Pugh,C.W. and Ratcliffe,P.J. (2003). The von Hippel-Lindau tumor suppressor, hypoxiainducible factor-1 (HIF-1) degradation, and cancer pathogenesis. Semin. Cancer Biol. 13, 83-89.

Qu,L., Huang,S., Baltzis,D., Rivas-Estilla,A.M., Pluquet,O., Hatzoglou,M., Koumenis,C., Taya,Y., Yoshimura,A., and Koromilas,A.E. (2004). Endoplasmic reticulum stress induces p53 cytoplasmic localization and prevents p53-dependent apoptosis by a pathway involving glycogen synthase kinase-3beta. Genes Dev. 18, 261-277.

Rao,R.V., Peel,A., Logvinova,A., del,R.G., Hermel,E., Yokota,T., Goldsmith,P.C., Ellerby,L.M., Ellerby,H.M., and Bredesen,D.E. (2002). Coupling endoplasmic reticulum stress to the cell death program: role of the ER chaperone GRP78. FEBS Lett. 514, 122128.

Reddy,R.K., Mao,C., Baumeister,P., Austin,R.C., Kaufman,R.J., and Lee,A.S. (2003). Endoplasmic reticulum chaperone protein GRP78 protects cells from apoptosis induced by topoisomerase inhibitors: role of ATP binding site in suppression of caspase-7 activation. J. Biol. Chem. 278, 20915-20924.

Risau,W. (1997). Mechanisms of angiogenesis. Nature 386, 671-674.

Romero-Ramirez,L., Cao,H., Nelson,D., Hammond,E., Lee,A.H., Yoshida,H., Mori,K., Glimcher,L.H., Denko,N.C., Giaccia,A.J., Le,Q.T., and Koong,A.C. (2004). XBP1 is essential for survival under hypoxic conditions and is required for tumor growth. Cancer Res. 64, 5943-5947. 
Roybal,C.N., Yang,S., Sun,C.W., Hurtado,D., Vander Jagt,D.L., Townes,T.M., and Abcouwer,S.F. (2004). Homocysteine increases the expression of vascular endothelial growth factor by a mechanism involving endoplasmic reticulum stress and transcription factor ATF4. J. Biol. Chem. 279, 14844-14852.

Semenza,G.L. (2001). HIF-1, O(2), and the 3 PHDs: how animal cells signal hypoxia to the nucleus. Cell 107, 1-3.

Semenza,G.L., Agani,F., Feldser,D., Iyer,N., Kotch,L., Laughner,E., and Yu,A. (2000). Hypoxia, HIF-1, and the pathophysiology of common human diseases. Adv. Exp. Med. Biol. 475, 123-130.

Shen,J.W., Subjeck,J.R., Lock,R.B., and Ross,W.E. (1989). Depletion of topoisomerase II in isolated nuclei during a glucose-regulated stress response. Mol. Cell Biol. 9, 32843291.

Shi,Y., Vattem,K.M., Sood,R., An,J., Liang,J., Stramm,L., and Wek,R.C. (1998). Identification and characterization of pancreatic eukaryotic initiation factor 2 alphasubunit kinase, PEK, involved in translational control. Mol. Cell Biol. 18, 7499-7509.

Shiu,R.P., Pouyssegur,J., and Pastan,I. (1977). Glucose depletion accounts for the induction of two transformation-sensitive membrane proteinsin Rous sarcoma virustransformed chick embryo fibroblasts. Proc. Natl. Acad. Sci. U. S. A. 74, 3840-3844.

Shuda,M., Kondoh,N., Imazeki,N., Tanaka,K., Okada,T., Mori,K., Hada,A., Arai,M., Wakatsuki,T., Matsubara,O., Yamamoto,N., and Yamamoto,M. (2003). Activation of the ATF6, XBP1 and grp78 genes in human hepatocellular carcinoma: a possible involvement of the ER stress pathway in hepatocarcinogenesis. J. Hepatol. 38, 605-614.

Sidrauski,C., Cox,J.S., and Walter,P. (1996). tRNA ligase is required for regulated mRNA splicing in the unfolded protein response. Cell 87, 405-413.

Sidrauski,C. and Walter,P. (1997). The transmembrane kinase Ire1p is a site-specific endonuclease that initiates mRNA splicing in the unfolded protein response. Cell 90, 1031-1039.

Siu,F., Bain,P.J., LeBlanc-Chaffin,R., Chen,H., and Kilberg,M.S. (2002). ATF4 is a mediator of the nutrient-sensing response pathway that activates the human asparagine synthetase gene. J. Biol. Chem. 277, 24120-24127.

Song,M.S., Park,Y.K., Lee,J.H., and Park,K. (2001). Induction of glucose-regulated protein 78 by chronic hypoxia in human gastric tumor cells through a protein kinase Cepsilon/ERK/AP-1 signaling cascade. Cancer Res. 61, 8322-8330.

Soung,Y.H., Lee,J.W., Kim,S.Y., Park,W.S., Nam,S.W., Lee,J.Y., Yoo,N.J., and Lee,S.H. (2004). Somatic mutations of CASP3 gene in human cancers. Hum. Genet. 115, 112-115. 
Sriburi,R., Jackowski,S., Mori,K., and Brewer,J.W. (2004). XBP1: a link between the unfolded protein response, lipid biosynthesis, and biogenesis of the endoplasmic reticulum. J. Cell Biol. 167, 35-41.

Tamatani,M., Matsuyama,T., Yamaguchi,A., Mitsuda,N., Tsukamoto,Y., Taniguchi,M., Che,Y.H., Ozawa,K., Hori,O., Nishimura,H., Yamashita,A., Okabe,M., Yanagi,H., Stern,D.M., Ogawa,S., and Tohyama,M. (2001). ORP150 protects against hypoxia/ischemia-induced neuronal death. Nat. Med. 7, 317-323.

Tirasophon,W., Welihinda,A.A., and Kaufman,R.J. (1998). A stress response pathway from the endoplasmic reticulum to the nucleus requires a novel bifunctional protein kinase/endoribonuclease (Ire1p) in mammalian cells. Genes Dev. 12, 1812-1824.

Travers,K.J., Patil,C.K., Wodicka,L., Lockhart,D.J., Weissman,J.S., and Walter,P. (2000). Functional and genomic analyses reveal an essential coordination between the unfolded protein response and ER-associated degradation. Cell 101, 249-258.

Urano,F., Wang,X., Bertolotti,A., Zhang,Y., Chung,P., Harding,H.P., and Ron,D. (2000). Coupling of stress in the ER to activation of JNK protein kinases by transmembrane protein kinase IRE1. Science 287, 664-666.

van,H.R., Martindale,J.L., Gorospe,M., and Holbrook,N.J. (2003). P58IPK, a novel endoplasmic reticulum stress-inducible protein and potential negative regulator of eIF2alpha signaling. J. Biol. Chem. 278, 15558-15564.

Vasudevan,K.M., Gurumurthy,S., and Rangnekar,V.M. (2004). Suppression of PTEN expression by NF-kappa B prevents apoptosis. Mol. Cell Biol. 24, 1007-1021.

Wang,C.Y., Mayo,M.W., Korneluk,R.G., Goeddel,D.V., and Baldwin,A.S., Jr. (1998a). NF-kappaB antiapoptosis: induction of TRAF1 and TRAF2 and c-IAP1 and c-IAP2 to suppress caspase-8 activation. Science $281,1680-1683$.

Wang,X.Z., Harding,H.P., Zhang,Y., Jolicoeur,E.M., Kuroda,M., and Ron,D. (1998b). Cloning of mammalian Ire1 reveals diversity in the ER stress responses. EMBO J. 17, 5708-5717.

Winzen,R., Kracht,M., Ritter,B., Wilhelm,A., Chen,C.Y., Shyu,A.B., Muller,M., Gaestel,M., Resch,K., and Holtmann,H. (1999). The p38 MAP kinase pathway signals for cytokine-induced mRNA stabilization via MAP kinase-activated protein kinase 2 and an AU-rich region-targeted mechanism. EMBO J. 18, 4969-4980.

Xu,C., Bailly-Maitre,B., and Reed,J.C. (2005). Endoplasmic reticulum stress: cell life and death decisions. J. Clin. Invest 115, 2656-2664.

Yamada,M., Tomida,A., Yun,J., Cai,B., Yoshikawa,H., Taketani,Y., and Tsuruo,T. (1999). Cellular sensitization to cisplatin and carboplatin with decreased removal of platinum-DNA adduct by glucose-regulated stress. Cancer Chemother. Pharmacol. 44, 59-64. 
Yan,W., Frank,C.L., Korth,M.J., Sopher,B.L., Novoa,I., Ron,D., and Katze,M.G. (2002). Control of PERK eIF2alpha kinase activity by the endoplasmic reticulum stress-induced molecular chaperone P58IPK. Proc. Natl. Acad. Sci. U. S. A. 99, 15920-15925.

Yancopoulos,G.D., Davis,S., Gale,N.W., Rudge,J.S., Wiegand,S.J., and Holash,J. (2000). Vascular-specific growth factors and blood vessel formation. Nature 407, 242-248.

Ye,J., Rawson,R.B., Komuro,R., Chen,X., Dave,U.P., Prywes,R., Brown,M.S., and Goldstein,J.L. (2000). ER stress induces cleavage of membrane-bound ATF6 by the same proteases that process SREBPs. Mol. Cell 6, 1355-1364.

Yoshida,H., Haze,K., Yanagi,H., Yura,T., and Mori,K. (1998). Identification of the cisacting endoplasmic reticulum stress response element responsible for transcriptional induction of mammalian glucose-regulated proteins. Involvement of basic leucine zipper transcription factors. J. Biol. Chem. 273, 33741-33749.

Yoshida,H., Matsui,T., Hosokawa,N., Kaufman,R.J., Nagata,K., and Mori,K. (2003). A time-dependent phase shift in the mammalian unfolded protein response. Dev. Cell 4, 265-271.

Yoshida,H., Matsui,T., Yamamoto,A., Okada,T., and Mori,K. (2001). XBP1 mRNA is induced by ATF6 and spliced by IRE1 in response to ER stress to produce a highly active transcription factor. Cell 107, 881-891.

Yun,H., Lee,M., Kim,S.S., and Ha,J. (2005). Glucose deprivation increases mRNA stability of vascular endothelial growth factor through activation of AMP-activated protein kinase in DU145 prostate carcinoma. J. Biol. Chem. 280, 9963-9972.

Yun,J., Tomida,A., Nagata,K., and Tsuruo,T. (1995). Glucose-regulated stresses confer resistance to VP-16 in human cancer cells through a decreased expression of DNA topoisomerase II. Oncol. Res. 7, 583-590.

Zinszner,H., Kuroda,M., Wang,X., Batchvarova,N., Lightfoot,R.T., Remotti,H., Stevens,J.L., and Ron,D. (1998). CHOP is implicated in programmed cell death in response to impaired function of the endoplasmic reticulum. Genes Dev. 12, 982-995. 


\section{VITA}

Nan Liao was born in Tianjin, China on March 23, 1980. After graduating from Nankai High School in 1998, he attended Nankai University in Tianjin, China, where he received his Bachelor of Science degree in Biochemistry and Molecular Biology in June of 2002. Later on, he worked as a Research Assistant in China Agro-Environment Protection Institute. In the fall of 2003, he entered the graduate program in the Department of Molecular Sciences at the University of Tennessee Health Science Center. In the summer of 2004, he joined the laboratory of Dr. Linda Hendershot. He received a Master of Science degree in Molecular Sciences in May of 2008. 